\title{
El sentido especulativo de la silogística en la Ciencia de la Lógica de Hegel
}

\author{
SERGiO MONTECINOS FABIO* \\ Universidad de Concepción (Chile) \\ montecinos.fabio.s@gmail.com
}

\begin{abstract}
Resumen
Se sostiene que la operación general de la silogística en la Lógica cumple con un programa trazado tempranamente por Hegel, consistente en concebir la unidad de la forma racional del silogismo y el contenido absoluto de la idea como resultado de una dialéctica inmanente a la propia forma del silogismo, mediante la cual éste abandona su carácter meramente formal y alcanza su propio concepto: ser forma objetiva o racional. Para esto se acude a la sección Subjetividad de la Doctrina del Concepto, procurando reconstruir los antecedentes sistemáticos del capítulo sobre el silogismo, así como la operación específica que éste realiza en vista del tránsito a la sección Objetividad. El sentido de dicha operación consiste en la superación de un exceso que, al comienzo, la necesidad de la sustancia tiene por sobre la libertad del concepto, de lo cual resulta un exceso del concepto por sobre la sustancia. Para verificar esta operación se examinan los silogismos del estar y la necesidad, concluyendo con la determinación del tipo de objeto y de conocimiento que resulta del silogismo, y con la proyección del problema a estadios ulteriores de la Lógica, en los cuales el problema avistado adquiere un cariz marcadamente práctico.
\end{abstract}

Palabras clave: Silogismo especulativo, idea, subjetividad, objetividad, antinomia necesidad / libertad, identidad de concepto y ser.

\section{The speculative sense of syllogistics in the Hegel's Science of Logic}

\begin{abstract}
In this paper I argue that the general operation of syllogistic in the Logic fulfills a philosophical program that was early outlined by Hegel. This program conceives the unity of the rational form of the syllogism and the absolute content of the idea as a result of an immanent dialectic to the syllogism's form, by which it abandons its merely formal character and attains its own concept: being an objective or rational form. For the purposes of this argument, I analyze the Subjectivity section of the Doctrine of the Concept and reconstruct the systematic background of the chapter on syllogism, as well as the specific operation it performs in view of the transit to the Objectivity section. This operation consists in overcoming a certain excess that the necessity of the substance has, first, over the freedom of the concept, which results in an excess of the concept over the substance. To clarify this operation, I examine the syllogisms of qualitative existence and necessity. Finally, I show the determination of the type of object and knowledge that results from the syllogism and explain how this problem projects to later stages of Logic, in which the analyzed problem acquires a relevant practical aspect.
\end{abstract}

Key words: Speculative syllogism, idea, subjectivity, objectivity, antinomy necessity / freedom, identity of concept and being.

Doctor en Filosofía por la Universidad Autónoma de Madrid, bajo la dirección del Prof. Dr. Félix Duque. El siguiente artículo es producto de una investigación posdoctoral en el Hegel-Archiv de la Ruhr-Universität Bochum, financiada por CONICYT (Beca Posdoctorado en el Extranjero). Entre sus últimas publicaciones se encuentran: "Religión, Absoluto y Filosofía en los fragmentos hegelianos Sobre la Religión" (2019), y "Máscaras del escepticismo en la filosofía de Hegel” (2019). 


\section{Planteamiento}

La importancia del silogismo para el pensamiento de Hegel se anuncia tempranamente en su filosofía. Ya en su segunda Tesis de Habilitación (1801) se sostiene que "el silogismo es el principio del idealismo" (Hegel, 1998a: 227) ${ }^{1}$. Intentar comprender el sentido y alcance de esta tesis abre un enorme campo dentro del corpus hegeliano, donde no fueron pocas las modificaciones introducidas por el autor conforme su pensamiento maduraba.

Por lo pronto, cabe relacionar la segunda tesis con la sexta, que reza: "la idea es síntesis de lo infinito y lo finito, y toda filosofía consiste en ideas" (Hegel, 1998a: 227). Si la filosofía consiste en ideas y el silogismo es el principio del idealismo, entonces debe existir una conexión profunda entre la forma racional del silogismo y el contenido absoluto de la idea, entendida como síntesis de lo infinito y lo finito. Precisamente porque la filosofía crítica cierra el acceso al contenido de la razón a través de silogismos $^{2}$, la séptima tesis afirma que "la filosofía crítica carece de ideas, y es

1 Para las obras de Hegel se utiliza la edición crítica (Gesammelte Werke). En general, las traducciones son nuestras, pero para la Lógica hemos cotejado el texto con la versión española de Félix Duque, adoptando no pocas veces su decisión de traducción. El detalle de la información bibliográfica de cada tomo puede consultarse en las Referencias.

2 Que para Kant los silogismos de la razón carecen de contenido objetivo (constituyen, pues, un uso trascendente de nuestra facultad de conocer) queda claro en los siguientes pasajes de la Crítica de la razón pura: "Al menos la realidad trascendental (subjetiva) de los conceptos puros de razón se basa en que nosotros somos llevados a tales ideas por un silogismo necesario. Habrá, entonces, silogismos que no contienen premisas empíricas, por medio de los cuales concluimos, desde algo que conocemos, algo de lo que no tenemos concepto alguno, a lo cual de todas formas otorgamos realidad objetiva por medio de una apariencia [Schein] inevitable" (1998: 441-2 [A339 / B397]); "No tratamos aquí con una dialéctica lógica que abstraiga de todo contenido del conocimiento y se limite a descubrir la apariencia falsa en la forma de silogismos de la razón, sino que nos ocupamos de una lógica trascendental que debe contener, completamente a priori, el origen de ciertos conocimientos a partir de la razón pura, así como conceptos inferidos cuyo objeto no puede ser dado empíricamente, o sea que se encuentran completamente fuera de la capacidad del entendimiento puro" (1998: 436 [A333 / B390]). Kant entiende al silogismo, la inferencia mediata (1998: 413ss. [A 303 / B360ss.]), como fuente de las ideas trascendentales y, por tanto, sede de la apariencia que lleva a la razón pura a creer que extiende su conocimiento gracias a ciertos principios incondicionados. Sin embargo, para Kant las ideas carecen de contenido determinado debido a que no corresponden a ningún objeto de la experiencia posible, pese a que su búsqueda y formulación pertenezca a la razón pura en virtud de su naturaleza, la cual le lleva a expandir al máximo posible el uso del entendimiento con la finalidad subjetiva (i.e. formal) de satisfacer absolutamente (i.e. incondicionadamente) su función sintética: "Los conceptos puros de la razón [...] se fundan en la naturaleza de la razón humana, a estos conceptos trascendentales puede, por lo demás, faltarles un uso concreto adecuado, de 
una forma imperfecta de escepticismo", que ha negado lo objetivo de la razón para afirmar lo subjetivo de la misma.

La insuficiencia del enfoque formalista de la filosofía crítica, apenas enunciada en las Tesis, adquiere sentido sistemático en un fragmento de las primeras lecciones dictadas por Hegel en Jena en el semestre de inverno de 1801/02. En un texto titulado Logica et Metaphysica (Hegel, 1998b: 269275), Hegel se propone explícitamente asumir (aufbeben) en una lógica de la reflexión finita - considerada como lado negativo de lo racional e introducción sistemática a una metafísica, por entonces el lado positivo de lo racional- no sólo los conceptos del entendimiento, sino también sus formas de síntesis: el juicio y el silogismo. En tal respecto, señala que en la lógica "el entendimiento o la reflexión finita [en cuanto] facultad del pensar finito es impulsado secretamente por la razón a alcanzar una identidad" pues "el entendimiento imita, en su finitud, a la razón al empeñarse en llevar sus formas a una unidad; pero la unidad que él puede producir es sólo una unidad formal o, lo que es lo mismo, una unidad finita, porque él se basa en la contraposición absoluta, en la finitud" (Hegel, 1998b: 272). Consecuentemente, Hegel formula un programa para llevar a cabo esta tarea, programa que, como segundo paso, propone examinar las "formas subjetivas de la finitud o el pensar finito, el entendimiento [...] en sus niveles a través de conceptos, juicios y silogismos" (Hegel, 1998b: 273), añadiendo a continuación que "en vista del silogismo debe notarse que si bien en ellos la forma racional se vislumbra más claramente, y por ello habitualmente [...] se los ha adscrito a la razón, nosotros mostraremos que, en la medida en que ellos son un mero silogizar formal, pertenecen al entendimiento" por lo que se trata allí de "una mera imitación de la razón por el entendimiento" (Hegel, 1998b: 273). Sólo en un tercer paso, una vez aniquilado el formalismo de las formas del entendimiento en general, podría investigarse "el significado especulativo de los silogismos" (Hegel, 1998b: 273-274), lo cual exhibiría la posibilidad de un tránsito desde el entendimiento a la razón y, con ello, la del inicio de un conocimiento especulativo.

En Jena, Hegel cumple parcialmente el programa indicado. En la sección titulada "Relación del pensar" de la Lógica de 1804/05 (parte del manuscrito fragmentario Logik, Metaphysik, Naturphilosophie) se lleva a cabo la asunción de las formas del entendimiento a través de un procedimiento dialéctico consistente en la subsunción recíproca de las determinaciones del concepto que son introducidas en el apartado dedicado al "Concepto determinado" (A) y están contenidas en el tratamiento del juicio (B) y el

modo que no tengan mayor utilidad que la de llevar al entendimiento en una dirección en la que, al ampliar su uso al extremo, este coincida completamente consigo mismo" (1998: 429 [B380]). 
silogismo (C). Se trata de un procedimiento negativo que busca aniquilar el formalismo del entendimiento para alcanzar lo positivo de lo racional, por entonces, como anunciamos, objeto de una Metafísica en cuanto ciencia especulativa. La dialéctica ensayada allí por Hegel alcanza el objetivo de negar lo fijo y limitado de cada una de las formas expuestas dentro de la "Relación del pensar", pero el silogismo no consigue exhibir en ello su "significado especulativo". Más bien, de su tratamiento resulta una nueva forma finita de la reflexión: "en cuanto mala realidad [Realität] del concepto, el silogismo ha regresado a su propio círculo; desde la absoluta desigualdad de sus extremos él ha devenido lo contrario" (Hegel, 1971: 106) ${ }^{4}$. Esto da paso a una nueva dialéctica dentro de la lógica de la reflexión finita, dialéctica que, bajo el título de Proporción, incorpora los procedimientos de la Definición y la División, de los cuales emerge a su vez el "conocer formal" (Goretzki, 2011: 167) o la reflexión finita como tal, aún afectada de exterioridad.

Ahora bien, pese a que Hegel utilice desde Jena el silogismo en el marco de una exposición especulativa ${ }^{5}$, habrá que esperar hasta la Ciencia de la Lógica para encontrar una reelaboración más satisfactoria del problema, capaz de incorporar las dos operaciones anunciadas tempranamente. Tal reelaboración es posibilitada por un nuevo marco teórico, a saber, el de una lógica que ya no es una introducción al sistema de la ciencia, sino la ciencia especulativa misma. ¿Cómo, en este contexto, poder establecer a través de la forma del silogismo el carácter objetivo de la razón tras la operación crítica kantiana?, ¿Qué clase de 'objeto' sería aquél que

$3 \quad \mathrm{Al}$ respecto, Düsing sostiene que "tampoco en su doctrina del silogismo [1804/05] Hegel alcanzó una prueba de la posibilidad e inteligibilidad del universal concreto que contiene en sí lo particular y lo singular” (1976: 176). Por su parte, Goretzki considera que la "relación del pensar" de la Lógica de 1804/05 supone ya cierta superación de la lógica del mero entendimiento, superación que sería ejecutada por la categoría de "infinitud" al final del apartado "referencia simple" (2011: 117-121). Por este motivo, tanto la "relación del ser" como la "relación del pensar" supondrían cierta demostración de la "validez objetiva" de las categorías que implicaría directamente la superación de la diferencia entre ser y pensar. Sin embargo, Goretzki subraya igualmente que el tratamiento del silogismo en la Lógica de 1804/05 no alcanza a mostrar su significado especulativo, por lo que asigna a la lógica expuesta en la "relación del pensar" un "carácter hermafrodita" que, por ser "al mismo tiempo algo intelectivo y algo racional" (2011: 151), no es propiamente ni lo uno ni lo otro.

4 Esto significa que el resultado del silogismo es allí una identidad finita. En tal sentido Goretzki sostiene: "las diversas operaciones del silogismo no desarrollan esta síntesis [exigida por los extremos del juicio]", de modo que "él [el silogismo] puede satisfacer sólo aparentemente la función sintética demandada por el juicio" (2011: 151).

5 Por ejemplo, en lugares tan decisivos como el capítulo "Fuerza y entendimiento" de la Fenomenología (Hegel, 1980: 102). 
corresponde a la forma especulativa del silogismo?, ¿Qué tipo de conocimiento resulta de tal correspondencia? Estas son las principales preguntas que buscaremos responder en el presente estudio. El objetivo general es, por tanto, mostrar cómo, en el tratamiento del silogismo en la sección Subjetividad de la Doctrina del Concepto de la Ciencia de la Lógica, Hegel reformula el problema relacionado con la forma del silogismo y el contenido de la razón de un modo tal que la exposición incorpora exitosamente las dos características que hemos anunciado y que formulamos del siguiente modo:

i) En primer lugar, que el silogismo tiene un sentido especulativo cuando es reconocido en su identidad con el contenido absoluto de la razón, idea presente en las Tesis de Habilitación.

ii) En segundo lugar, que esta identidad entre la forma del silogismo y el contenido de la razón es el resultado del desarrollo del silogismo en cuanto asunción (Aufhebung) de su formalismo, lo cual viene sugerido tanto en el programa de Logica et Metaphysica como en el intento — no logrado en vista del programa - de la Lógica de 1804/05.

Para llevar a cabo esta tarea formularemos, en primer lugar, el problema del silogismo en la sección Subjetividad, deduciendo a su vez el tratamiento del silogismo a partir de los del concepto y el juicio. En segundo lugar, atenderemos al modo específico en que se lleva a cabo la asunción de su carácter formal concentrándonos en el silogismo del estar (Dasein) y el silogismo de la necesidad. Finalmente, desprenderemos algunas consecuencias metódicas de la operación tematizada, lo cual está íntimamente ligado al tipo de objeto y de conocimiento que resultan de una consideración especulativa del silogismo.

\section{EL PROBLEMA DEL SILOGISMO EN LA SECCIÓN SUBJETIVIDAD}

El problema de la forma y el contenido de la razón es clave para comprender el sentido y la función de la sección Subjetividad en la Lógica. Esto se refleja en el inicio del capítulo dedicado al "concepto en cuanto tal"6 (Hegel, 1981: 32), donde Hegel alude a una doble caracterización de corte kantiano- del entendimiento. La primera caracterización anticipa la división de la sección Subjetividad en concepto, juicio y silogismo dado que el entendimiento en tanto "facultad de los conceptos en general" también contiene los momentos de la "facultad de juqgar" y "de la facultad

Seguimos la denominación del propio Hegel para diferenciar el tratamiento del concepto dentro de la sección Subjetividad de la introducción general a la Doctrina del Concepto, titulada "Del concepto en general". 
de los silogismos, en cuanto razón formal". Esto es así porque "el juicio y el silogismo o razón son ellos mismos, entendidos como algo formal, solamente una cosa propia del entendimiento" (Hegel, 1981: 32).

La segunda caracterización adelanta el sentido general de la sección Subjetividad al realizar una distinción entre entendimiento y razón: el entendimiento sería, en general, una facultad de conceptos determinados que "es preferentemente contrapuesta a la razón" (Hegel, 1981: 32). Cabe comprender aquí bajo "razón" una facultad de conceptos indeterminados en el sentido kantiano de las ideas: conceptos universales que no encuentran su exposición (Darstellung, exbibitio) en intuición alguna (Kant 2009: 37) ${ }^{7}$, hallándose por tanto fuera del ámbito de la experiencia posible. Pero el problema es algo más complejo, pues el propio Hegel había señalado que el silogismo intelectivo también es considerado como "razón formal", de modo que el entendimiento contendría en sí al menos la forma de la razón. Visto así el asunto, la contraposición entre razón y entendimiento concerniría más al contenido de la razón misma, que permanecería cerrado para una "razón formal".

En el inicio del tratamiento del silogismo Hegel retoma este problema. Allí sostiene, sin ambages, que el silogismo es "lo racional" e incluso que "todo lo racional es un silogismo" (1981: 90), pero inmediatamente menciona cierta ambigüedad concerniente al concepto mismo de razón, ambigüedad que se refleja muy bien en las posiciones contrapuestas de la filosofía crítica y el racionalismo: de un lado "desde hace largo tiempo se ha adscrito a la razón el silogizar, mas del otro lado se habla de la razón en y para sí, de principios [Grundsätzen] y leyes racionales", pues calificamos como 'racional' o 'razonable' aquello que demanda, en principio, un común acuerdo, siendo, en tal sentido, algo objetivo. Pero si la razón ha de ser exclusivamente formal, entonces ella, por medio de meros silogismos, sólo puede llegar a pensamientos vacíos (conceptos indeterminados), jamás al contenido de lo racional. Y entonces, no se vislumbra "cómo se conectan entre sí aquella razón que silogiza y esta razón que es fuente de leyes y otras verdades eternas, así como de pensamientos absolutos" (Hegel, 1981: 90), ya que esta última razón requiere de una objetividad de la cual la primera carece ${ }^{8}$. Tal conexión demanda, a juicio de Hegel, la unidad de ambos sentidos de

\footnotetext{
$7 \quad \mathrm{Al}$ respecto, véase, Wildenauer, 2004: 51-54.

8 Hegel hace exactamente el mismo diagnóstico, ahora en un sentido inverso, en el inicio de la sección Objetividad (1981: 132): por un lado, reconocemos como 'objetivo' aquello enfrentado al concepto, que es independiente de toda subjetividad, pero "en un sentido contrapuesto" comprendemos como 'objetivo' aquello que "es en y para sí, que es sin limitación ni oposición", como p. ej. "principios racionales" u "obras de arte perfectas", es decir, objetos o principios en los que reconocemos la forma de la racionalidad.
} 
la razón, lo cual implica que el contenido de la razón debe necesariamente tener también la forma del silogismo:

Si aquélla debe ser tan sólo la razón formal, y ésta debe empero engendrar [erzengen] el contenido, entonces según esta diferencia a la última no podría faltarle, justamente, la forma de la razón, el silogismo. A pesar de ello, ambas suelen estar mantenidas tan separadas [...] que la razón de los pensamientos absolutos parece avergonzarse de la razón del silogismo. (Hegel, 1981: 90)

Esta exigencia permite comprender el sentido general de la sección Subjetividad porque en ella se busca tanto superar la consideración formal del concepto, como la consideración indeterminada del contenido de la razón. Desde esta perspectiva, el silogismo, en cuanto "concepto completamente puesto" (Hegel, 1981: 90) no sólo tendría la tarea de mostrar que el concepto es concreto según su forma, y por tanto es uno con el juicio y el silogismo ${ }^{9}$ — como veremos — sino también que es la manifestación del contenido determinado de la razón, de manera que concepto, juicio y silogismo no se limitan a meras formas intelectivas.

Pero más específicamente, el pasaje señala que los pensamientos absolutos de la razón han de encontrarse abiertos a la forma del silogismo, lo cual no es posible si se considera que la razón es meramente formal y que el contenido absoluto de tales pensamientos racionales es indeterminado. Hegel critica aquel "conocimiento que supuestamente debe ser racional" pero "olvida conocer la razón misma, distinguiéndose [...] sólo por los objetos que tiene". Este presunto conocimiento sólo tiene "representaciones y sentimientos" de sus "objetos negativos", tales como son "Dios, la libertad, el derecho y el deber, lo infinito, incondicionado y suprasensible" (Hegel, 1981: 91). Al respecto, Hegel recomienda que, antes de determinar tales objetos como objetos negativos, ha de preguntarse qué es lo que los diferencia de otros objetos: "en virtud de qué son ellos racionales" (1981: 91). Y su respuesta es que tales objetos son racionales o infinitos no porque sean una "abstracción vacía", sino porque son una "universalidad llena" (1981: 91) y sólo así considerada "la razón se eleva por sobre lo finito, condicionado, sensible" (1981: 91). Esta "universalidad llena" sólo está llena si es que exhibe la forma del silogismo, lo que al mismo tiempo permite exponer, en cuanto movimiento del contenido, el proceso de elevación mencionado.

$9 \quad \mathrm{Al}$ respecto, véase Stekeler-Weithofer, 2009. 
Ahora, que el contenido de la razón se encuentre abierto a una forma de conocimiento suscita interrogantes: ¿Implica esta idea un regreso al racionalismo pre-crítico? Desde la perspectiva en que Hegel desarrolla su concepción del silogismo consideramos que la respuesta es negativa, pues no se trata de que la razón, a través del silogismo, alcance el conocimiento de un objeto infinito en el sentido de un ente allende la experiencia ${ }^{10}$, cuyos predicados, e incluso su mera existencia, vinieran a ser deducidos a partir de premisas ${ }^{11}$. Más bien, el contenido de la razón, lo incondicionado e infinito, consiste en la articulación inmanente de lo finito mismo, lo cual acontece en procesos objetivos que han de ser tematizados según la forma del silogismo para exbibir su naturaleza racional. Por eso Hegel señala que "todo contenido puede ser racional sólo por medio de la forma de lo racional" pues "el concepto, que está determinado, tiene la determinidad en él de un modo tan pleno de verdad que se diferencia dentro de sí mismo y es la unidad de estas sus diferencias [...]" (1981: 90-91). Desde este punto de vista, la sección Subjetividad, en particular el capítulo dedicado al silogismo, puede entenderse como un autoconocimiento de la razón en el sentido de una autodeterminación pura o formal. Mas lo característico del enfoque especulativo hegeliano consiste en que es la propia exploración de la forma de lo racional lo que mostrará su verdadera relación con el contenido absoluto, ejecutando con ello la elevación del entendimiento a la razón.

\subsection{El contenido de la razón y la Doctrina del Concepto}

Cabe preguntarse por la proveniencia del contenido absoluto de la razón. Hemos indicado que no se trata de un objeto trascendente, pero debemos aclarar su naturaleza en el contexto de la Lógica de Hegel. Esto nos traslada a la división bipartita de la Lógica en una Lógica Objetiva (Ser y Esencia) y una Lógica Subjetiva (Concepto). Considerando el desarrollo desde la Lógica Objetiva a la Subjetiva es posible afirmar que el contenido

\footnotetext{
10 Tal es la crítica de Kant cuando sostiene que el Ideal de la razón pura consiste en la búsqueda de una "cosa singular" (o individual: einzelnes Ding) que "contenga en sí toda la realidad empírica", la cual se encontraría, en virtud de lo elevado de su concepto, "en la cúspide de la posibilidad de todas las cosas" (1998: 661 [A583 / B611]).

11 En un sentido similar, Okochi ha sostenido que, contrariamente al realismo dogmático, la lógica de Hegel no puede adscribirles realidad a las formas lógicas "sin una reflexión sobre las condiciones subjetivas de las determinaciones del pensamiento". Pero al mismo tiempo - ahora contra el idealismo subjetivo- tampoco puede detenerse en la mera consideración formal de tales formas (2019). Agradezco al Prof. Okochi por haberme enviado el manuscrito de su presentación en la Universidad de Jena.
} 
absoluto de la razón no debe ser tomado de ningún sitio exterior a la exposición lógica, puesto que ya se encontraba en ella desde su inicio, habiéndose desarrollado hasta revelar su carácter conceptual.

En la Doctrina del Concepto el concepto ha de poner según su "determinación libre" los momentos de la Lógica Objetiva que al llegar a la "relación de sustancialidad", en el final de la Lógica de la Esencia, fueron expuestos según la determinación de la necesidad (Hegel, 1981: 29). Con el tránsito al concepto, las categorías de la Lógica Objetiva pierden su basamento (Grundlage) en la sustancia, ya que el concepto mismo sale a la luz como basamento originario: "Este devenir [del Concepto desde el Ser y la Esencia] tiene [...] la significación de ser el contragolpe [Gegenstoß] de sí mismo, de modo que lo devenido es más bien lo incondicionado y originario" (Hegel, 1981: 33). Como sostiene Nuzzo (2003: 173) ${ }^{12}$, la tarea consiste entonces en restablecer el contenido absoluto de la Lógica Objetiva a través de las determinaciones del concepto en su dialéctica propia, a saber, la dialéctica del desarrollo $^{13}$. Tales determinaciones del concepto son universalidad $(=\mathrm{A})$, particularidad $(=\mathrm{B})$ y singularidad $(=\mathrm{E})^{14}$, de modo que, podría sostenerse, dentro de la Doctrina del Concepto, la sección Subjetividad tiene la tarea específica de llevar a cabo esta reconstrucción a través de las determinaciones puras del concepto, esto es: en la medida en que ellas han abstraído todo contenido sustancial y se han manifestado como la forma subjetiva pura de las relaciones que antes tuvieron lugar en la sustancia. Por eso Hegel caracteriza este nivel de tematización del concepto como "formal" (1981: 30), lo cual ofrece la oportunidad de hacer una importante distinción.

En el contexto de nuestro problema, 'formal' ha de entenderse en dos sentidos, vinculados entre sí: i) 'formal' en cuanto auto-tematización pura de las determinaciones del concepto y sus relaciones; ii) pero también formal en cuanto 'todavía o meramente formal' ${ }^{15}$. Este último sentido indica

12 Concretamente, Nuzzo sostiene que, una vez de-puesta la objetividad a través del curso de la Lógica Objetiva, ella debe ser re-puesta en el Concepto. Esta re-posición daría paso a una forma de existencia dentro del concepto, cuya primera determinación sería la Objetividad en general. En otro lugar, Nuzzo vincula esta operación de "reconstrucción de la realidad desde el concepto" (1995: 117) en cuanto "autoproducción objetiva del concepto mismo" con el sentido de la prueba ontológica de la existencia de Dios en el contexto de la Ciencia de la Lógica de Hegel.

13 Para la distinción entre la dialéctica del tránsito (Übergehen), de la reflexión (Reflexion) y del desarrollo (Entwicklung) en cuanto tipos de dialéctica pertenecientes, respectivamente, a la lógica del Ser, la Esencia y el Concepto; véase Schäfer, 2001: 295319.

14 Siguiendo la convención, mantenemos las iniciales de los términos en alemán: Allgemeinheit, Besonderheit y Einzelheit.

15 En un sentido similar, Schäfer diferencia, a propósito del juicio y la función de la cópula, dos aspectos de la identidad de la subjetividad en la Doctrina del Concepto: por 
que la red formada por las determinaciones del concepto y sus relaciones todavía no ha abarcado la entera extensión del contenido antes puesto como sustancia y necesidad, por tanto, que el contenido sustancial aún no ha sido enteramente penetrado por la forma del concepto.

Esto último explica por qué Hegel realiza dos distinciones: la primera (véase, p. ej. 1981: 55; 57ss.) sostiene que las formas del concepto, juicio y silogismo tienen un significado subjetivo y uno objetivo, es decir, las determinaciones del concepto son determinaciones de las cosas mismas, pero también determinaciones de nuestro modo de pensarlas. La segunda distinción, en cambio, señala que mientras el concepto no se haya mediado suficientemente en sí mismo, permanecerá siendo algo incompleto (véase p. ej. 1981: 20-21), pues el contenido objetivo aún permanece exterior a la forma y esto implica al mismo tiempo que las conexiones exhibidas en el contenido aún requieren, al menos en parte, de la reflexión exterior de un tercero, reflexión que no aún no ha sido puesta por la forma como determinidad inmanente del contenido.

Lo anterior nos ofrece también la meta de la sección Subjetividad: las determinaciones del concepto deben mediarse recíprocamente hasta abarcar la totalidad del contenido sustancial. Con esto el concepto en cuanto lo libre "constituye la identidad de la sustancia, al mismo tiempo como asumida o como ser-puesto" (Hegel, 1981: 15). Notemos entonces que, para el concepto formal, el contenido objetivo de la sustancia presenta una suerte de exceso (Überschuss) y esto indica cierta falta de desarrollo de la forma. La pregunta, por tanto, es cómo es que la forma se desarrolla hasta asumir dicho exceso. Este desarrollo de la forma constituye el contenido de la sección, pues las figuras del concepto, el juicio y el silogismo ejecutan la mediación interna del concepto, que avanza hacia mayores grados de concreción.

Pero si el exceso mencionado implica todavía una exterioridad entre la forma y el contenido de la razón: ¿Cómo puede afirmarse que las formas puras no son vacías?

un lado, se trata de una identidad noética en el sentido de la subjetividad que piensa y ejecuta las relaciones lógicas presentes en lo pensado. Por otro lado, se trata de una identidad noemática por cuanto lo pensado mismo exhibe en su contenido las operaciones ejecutadas por el pensar. De tal suerte, "la identidad noética se realiza en la noemática, mientras que la identidad noemática requiere de la identidad noética para llevarse a cabo en general". Ahora, Schäfer apunta también a la diferencia que caracterizamos como un carácter 'todavía formal', por cuanto "la 'diferencia' entre la identidad noética y la noemática configura el carácter abstracto del concepto, lo cual constituye su deficiencia y finitud originaria en la entera Doctrina del Concepto". Tal diferencia vendría a ser completamente superada por el concepto "recién en la 'Idea" (2006: 54). 
$\mathrm{Al}$ respecto, lo primero es remarcar que el contenido de las determinaciones del concepto es, naturalmente, un contenido lógico-especulativo y ello, tal vez, de un modo paradigmático en relación con el resto de conceptos de la lógica. Se trata de pensamientos que no son exteriores a la realidad que es pensada a través de ellos: en el caso de las determinaciones del concepto, veremos, por ejemplo, que la singularidad expone el primer núcleo de contenido conceptual concreto ${ }^{16}$, el cual deberá ir mediándose con determinaciones conceptuales de mayor extensión hasta elevarse a universalidad. Esta elevación puede considerarse también como una expansión del contenido puesto al inicio de la Lógica del Concepto — tras la "de-posición" de lo sustancial— como algo singular.

Pero hay además un aspecto más general que debe ser igualmente considerado. Ya en la Introducción a la Lógica, Hegel (1978: 19ss.) subraya su carácter no formal: el pensar, que es el objeto de la exposición, no es exterior al $\operatorname{ser}^{17}$, pese a que dentro de la exposición puedan distinguirse pensamientos determinados como presentes inmediatamente en la objetividad y pensamientos que exponen la actividad de la subjetividad (tal es precisamente el fundamento de la división de la Lógica en una Lógica Objetiva y una Subjetiva ${ }^{18}$ ). Por tanto, si en general los conceptos de la Lógica son formas inmanentes al contenido objetivo del pensar, esto vale de modo

16 En tal sentido, Goretzki caracteriza la singularidad como una "sustancia lógica" (2011: 114).

17 En "Del concepto en general" Hegel igualmente sostiene: "Aquí la objetividad del pensar se encuentra expresada de un modo determinado como siendo una identidad entre el concepto y la cosa, identidad que es la verdad' (1981: 23). Probablemente la formulación más pregnante de esta idea se encuentra en la Introducción a la segunda edición de la Lógica del Ser (1832): "En general, subyace al uso de las formas del concepto, el juicio, el silogismo, la definición, división, etc. el que ellas no son meras formas del pensar autoconsciente, sino también del entendimiento objetivo" (Hegel, 1984: 35, agrego cursivas). Cabe agregar que la concepción de un "pensar objetivo" se da como se da como resultado de la Fenomenología, de la exploración en la no-verdad de los modos finitos del conocer, la asunción de la contraposición de la conciencia y la simplificación de la figura en el pensamiento puro.

18 Esta división de la lógica se encuentra ya en la primera de las lógicas propedéuticas de Nuremberg y proviene directamente del intento de Hegel por conectar la exposición lógica con el resultado alcanzado en la sección Razón de una exposición fenomenológica abreviada, que operó entonces como una introducción a la lógica. En efecto, en el $\$ 29$ de la Mittelklasse Logik de 1808/09 se sostiene que las “determinaciones de la razón” son tanto "pensamientos propios" (eigne Gedanken) como "determinaciones de la esencia de las cosas" (Hegel, 2006: 29). Por este motivo, el conocimiento de estas determinaciones puras debería contener tanto un respecto subjetivo como uno objetivo, como afirma el \$30: "Las determinaciones lógicas [...] son de doble clase: de una clase lo son en la medida en que pueden ser adscritas al ente; de otra clase, en la medida en que pueden ser adscritas al pensar; en lo cual, sin embargo, la razón tiene la conciencia de que estas determinaciones convienen a ambos lados" (2006: 29). Al respecto, véase Giuspoli, 2002: 77-106. 
eminente para las formas puras de la Subjetividad en cuanto apartado específico de la exposición lógica. Las formas puras de la subjetividad (concepto, juicio, silogismo) tienen un valor objetivo porque manifiestan cosas, procesos o estados de cosas (Sachverhalte) determinados, pero también son finitas, de manera que su total compenetración con el contenido sustancial requiere de la superación de su finitud, vale decir, la asunción del exceso que el contenido sustancial tiene frente a las formas subjetivas puras. Sólo de este modo ellas devienen forma y contenido de la razón.

\subsection{Deducción del silogismo a partir del concepto y el juicio}

Hemos señalado la intención hegeliana de abarcar con la determinidad de la forma conceptual la totalidad del contenido sustancial; hemos señalado además que las formas puras del concepto presentan ya un contenido expresamente conceptual, si bien no completamente desarrollado en el inicio de la sección Subjetividad. Pues bien, lo primero a destacar ahora es cómo el concepto determina su forma pura como contenido, operación que se presenta en el capítulo dedicado al "concepto en cuanto tal" como una autodeterminación del concepto como singularidad.

En este capítulo el concepto lleva a cabo una autodeterminación todavía inmediata: él se determina dentro de sí como universalidad, particularidad y singularidad asumiendo cada una de sus determinaciones en la otra $^{19}$. Mas, en cuanto resultado, la singularidad exhibe la siguiente peculiaridad: frente a la pura negatividad de lo universal y frente a la fijación de sus momentos como particularidades, lo singular es la primera concreción del concepto, "el principio de la individualidad y personalidad" (Hegel, 1981: 49). En ella el concepto está "dentro de sì" (Hegel, 1981: 51) en el sentido de que sus momentos anteriores están reunidos y especificados como algo único. Con esto, el concepto llega, dentro de su inmediatez, a un núcleo de concreción que expone la partícula más simple del contenido puesto explícitamente por él: un algo que consiste en la mostración (Monstration) de sí mismo.

Sin embargo, Hegel sostiene igualmente que la singularidad no es "solamente el retorno del concepto a sí mismo sino, inmediatamente, su pérdida" (1981: 51). En lo singular, el concepto también "está fuera de sî" debido a que lo singular es el núcleo negativo más básico, que se abstrae de todo lo otro para ponerse como una inmediatez simple. Al ponerse

19 Este sentido, Schick señala: "Lo universal, lo particular y lo singular se han mostrado cada uno, al final, como la unidad reestablecida por medio de la negación de la negación; cada uno de los momentos se ha conservado como la totalidad de todos los momentos" (1994: 223). 
como singular, el concepto se parte: su universalidad se ha perdido porque se hace concreta en un solo punto excluyente, mientras que su particularidad contiene también la posibilidad de otras concretizaciones. El concepto se pierde porque se separa de sí mismo al concretizarse como un "esto" (Dieses) asilado ${ }^{20}$.

Ahora bien, aunque las tres determinaciones del concepto constituyen en general la base de las operaciones de la entera Doctrina del Concepto, en el "concepto en cuanto tal" ellas todavía no constituyen una realidad del concepto. Esto es así porque en ellas el concepto aún no se ha determinado en la determinación particular, lo cual sucede sólo en la singularidad: singularidad es determinación determinada, señala Hegel (1981: 49). Esta es la razón por la que se sostiene que sólo en ella el concepto "entra en la realidad efectiva [Wirklichkeit]" (1981: 51).

Pero si lo singular se muestra desde sí mismo frente a otro, del que puede diferenciarse o al que puede igualarse: ¿Cómo es posible tal mostración más allá de la mera indicación de un 'esto'? Lo singular constituye sólo una primera manifestación de la autodeterminación concreta del concepto, que es fundamental para formas más complejas, pero requiere profundizar en sí mismo para mostrar la determinación de su contenido.

Pues bien, decíamos que, al entrar en la realidad efectiva, el concepto se ha perdido porque la determinación de lo universal en lo singular a través de lo particular ha quedado asumida en la inmediatez de lo singular. Hegel entiende este movimiento como una separación de las determinaciones del concepto a partir de la cual la relación entre lo universal y lo singular debería volver a explicitarse, pero ahora en la realidad efectiva del singular en cuanto sujeto. Un singular se muestra a sí y se diferencia de otro a través de sus determinaciones: el singular requiere entonces de determinaciones para mostrar lo que él es específicamente cada vez y por este motivo exhibe una referencia a la particularidad y la universalidad. Pero como el concepto se ha partido, entonces tales determinaciones se presuponen como separadas y autosubsistentes, de modo que la autodeterminación del concepto en este nivel consiste en referir estas determinaciones del concepto desde su separación. Dicha referencia es el juicio.

El juicio muestra la Cosa al vincular determinaciones del concepto. A través de la cópula, el concepto restablece su identidad desde la separación de sus determinaciones, pues para mostrar lo que la cosa es ha de referirse un universal a la unidad concreta del singular: sólo el concepto predicado exhibe lo que la cosa (el concepto sujeto) es, no su mero nombre. Se trata,

20 Schick (1994: 226) detecta en esta contradicción entre universalidad y singularidad el establecimiento formal de la diferencia entre Cosa (Sache) y concepto, entendiéndola como una diferencia interna del concepto. 
por tanto, de una autodeterminación mediada por la cópula, que, por su parte, indica tanto la referencia como la separación de las determinaciones del concepto puestas en juego.

Hegel llama al juicio "la más próxima realización [Realisierung] del concepto, en la medida en que la realidad [Realität] designa en general el ingreso en el estar como ser determinado" (1981: 53). El motivo de una "realización del concepto" 21 comienza desde aquí a ser recurrente para referirse a los grados en que "el concepto ha de producir [herzustellen] [...] el libre ser-para-sí de su subjetividad" (1981: 132)22. En este primer nivel de realización, el juicio muestra cómo el núcleo de la realidad efectiva presente en lo singular se media con determinaciones de mayor extensión, y con ello es la realidad misma, en su respecto formal, la que gana más determinidad y diferenciación, estrechando así el exceso que lo sustancial tiene frente a lo formal del concepto. El juicio nos ofrece, a través de sus combinaciones, diversos modos en los que el concepto aparece como estar determinado, es decir, cómo lo singular contiene universalidad y lo universal se determina en la realidad efectiva (véase Hegel, 1981: 60). Este avance en determinación a través de los cuatro grupos de juicios conduce — como anunciamos- a la igualación (Gleichsetzung) de los extremos del sujeto y el predicado en cuanto "llenado" (Erfüllung) de la cópula 23 . Sin embargo, la identidad alcanzada no consigue hacer desaparecer completamente la separación de los extremos, pues al juicio le es esencial mantener la cópula como acto de la determinación y ella sólo refiere lo que se encuentra separado.

La insuficiencia formal del juicio puede explicarse desde varias perspectivas $^{24}$. Quisiéramos subrayar una relacionada directamente con el sentido en que el silogismo da un paso más allá del juicio.

21 Cabe señalar que la Lógica de 1804/05 contiene ya el motivo de la realización como un hilo conductor de la dialéctica de los conceptos de la reflexión finita. Por otra parte, las diversas lógicas propedéuticas de Nuremberg muestran que, en las primeras exposiciones lógicas del período, el motivo de la realización del concepto había perdido presencia, alcanzando centralidad luego en conexión con el problema de fin (Zweck). Esto se verifica por lo menos a partir de 1810/11 (véase Hegel, 2006: 182) y sobre todo en las anotaciones y modificaciones que Hegel realizó a sus diversos manuscritos entre los años 1811 y 18015 a fin de actualizar su material docente a la nueva arquitectónica de la lógica, que ya tomaba una forma más acabada. Al respecto, véase Rameil, 1993.

22 En este sentido, Martin (2012: 297).comprende la "realización" como el grado de conexión entre la constitución particular de una cosa y su naturaleza universal.

$23 \mathrm{Al}$ respecto, véase Schäfer, 2006.

$24 \mathrm{Al}$ respecto puede consultarse: Iber, 2009: 120; Martin, 2012: 302; Schick, 2002: 222; 2018: 507-508; Düsing, 1976: 265s. 
Como detecta De la Maza (2004: 35), desde su época en Frankfurt ${ }^{25}$ Hegel comprendió que la estructura del juicio constituye una fijación de cierta relación entre sujeto y predicado, lo cual le impide conocer sus objetos de un modo que no se encuentre determinado por los productos fijos que produce. Así, por ejemplo, en el Differenzschrift, Hegel (1986: 24-27) entiende los productos del juicio como un ser-puesto por la reflexión finita al que necesariamente otro le queda contrapuesto. En el contexto del tratamiento del juicio en la Lógica esta crítica puede complementarse con el siguiente pasaje:

El juicio tiene en general como sus extremos a totalidades, que al principio son esencialmente autosubsistentes. Por eso la unidad del concepto es primero sólo una referencia entre términos autosubsistentes; aún no es la unidad concreta, llena, retornada a sí desde esta realidad, sino una unidad fuera de la que ellos, en cuanto extremos no asumidos en ella, subsisten. (Hegel, 1981: 54-55)

Las determinaciones del concepto, que ocupan cada vez la posición de sujeto y predicado en el juicio, subsisten separadamente como sus extremos, de modo que la referencia entre ellas a través de la cópula es, por lo pronto, una referencia que no agota las totalidades que ellas mismas son, sino que las refiere puntualmente. Esto implica que el juicio presenta en sus figuras diversos modos en que las cosas finitas aparecen en el estar y son pensadas por nosotros, pero cada uno de estos modos conforma una instancia puntual y asilada de otras ${ }^{26}$. Dicha separación de cada instancia puntual de la aparición es lo que Hegel entiende como carácter inmediato y vacio (i.e. no determinado, o no enteramente determinado) de la cópula: la

25 Se trata de la crítica al leguaje proposicional (i.e. el lenguaje de la reflexión finita) que Hegel dirige en el contexto de un análisis del comienzo del Evangelio de San Juan. Lo fundamental es que el lenguaje de la reflexión no alcanza dar con la unidad viva y absoluta contenida en el inicio del Evangelio ("En el comienzo fue el Logos, el Logos estaba en Dios, y Dios era el Logos, en Él estaba la vida") porque es un lenguaje que separa en "proposiciones téticas" aquello que en lo absoluto es una unidad internamente diferenciada. Por este motivo sostiene que en el comienzo del Evangelio "estas proposiciones sólo tienen la confundente apariencia de juicios, pues los predicados no son conceptos, no son un universal al modo en que la expresión de una reflexión necesariamente contiene; sino que los predicados son ellos mismos algo que es, algo viviente" (Hegel, 2014: 254).

26 Concretamente esto implica que el juicio puede dar cuenta de cosas aisladas o relaciones asiladas (movimiento acotados) entre cosas, pero no de procesos continuos. En este sentido, Martin caracteriza al juicio como una "movilidad finita" (endliche Bewegheit), motivo por el cual "el automovimiento puro del concepto no se deja expresar en su continuidad ni en un juicio aislado ni en una hilera de juicios, sino sólo en el silogismo en tanto encadenamiento de contenidos abiertos a la forma del juicio" (2012: 304). 
cópula es lo que media los extremos del juicio, de modo que su vaciamiento e inmediatez indica que la relación entre los extremos no surge desde la interioridad del elemento mediador, sino se da, por así decirlo, "desde fuera hacia dentro", como formas insuficientes de producir la identidad entre concepto y ser, entre predicado y sujeto. Por este motivo, como subraya Schäfer (2006: 55), un sujeto puede corresponder a diversos conceptos predicados y, a su vez, un concepto predicado puede predicarse de diversos sujetos, pues la cópula, en cuanto referencia indeterminada, no contiene expresamente en sí las relaciones necesarias entre los extremos del juicio.

Lo que se requeriría, entonces, es que la cópula misma fuese una unidad objetiva plena en determinidad; entonces podría establecerse la diversidad de juicios como desarrollo interno de un todo que se continúa en su diferenciación. Pero debido a la inmediatez de la cópula sucede más bien lo inverso: el tratamiento del juicio consiste en ir llenando paulatinamente la cópula a partir de instancias puntuales de identificación entre sujeto y predicado.

No obstante lo anterior, debido a que se trata de un movimiento puesto por el concepto, él también configura un desarrollo, por lo que Hegel lo caracteriza igualmente como una mostración. Esta mostración no es, sin embargo, la exposición de procesos continuos, sino que consiste en discontinuidades que llenan cada vez un 'espacio' de la cópula al incorporar formas de relación entre determinaciones del concepto. En tal respecto, el proceso muestra que la completa nivelación de los extremos del juicio a través del llenado de la cópula es, al mismo tiempo, su desaparición: "desde ahora está presente la cópula determinada y plenificada, antes consistente en el abstracto es, pero que ahora se ha formado ulteriormente hasta hacerse fundamento en general. [...] Así ha ido a su ocaso la forma del juicio" (Hegel, 1981: 88). Podríamos decir, entonces, que el juicio muestra que la cosa, considerada como una instancia puntual, no puede corresponder cabalmente a su concepto; es la irremediable fractura de todo lo finito, entre concepto y ser o esencia y existencia. Y si esta separación entre concepto y ser es asumida, entonces la forma del juicio también lo es. Con ello emerge la condición formal para una tematización completa de la autodeterminación del concepto: el silogismo.

\section{LA ASUNCIÓN DEL SILOGISMO FORMAL}

Hemos caracterizado el sentido general de la asunción del silogismo formal en el marco de la sección Subjetividad, así como la deducción del silogismo a partir del concepto y el juicio. Corresponde ahora reconstruir los principales momentos del proceso de asunción caracterizado, a fin de verificar lo planteado y comprender más concretamente las operaciones 
involucradas. Para ello ofreceremos una caracterización general del silogismo y su esquema en tres figuras, enfocándonos posteriormente en los silogismos del estar y de la necesidad.

\subsection{El silogismo en general}

Con el silogismo el concepto alcanza la posibilidad de asumir su carácter formal, precisamente debido a que es la forma completa de la subjetividad: el restablecimiento de la unidad del concepto desde el juicio. Hegel llama al silogismo "concepto completamente puesto" (1981: 90), pues en él se alcanza una estructura de mediación que permite vincular aquello que el juicio sólo puede presentar en instancias puntuales de identificación: "el silogismo es mediación" (1981: 126). Esta estructura de mediación se relaciona directamente con el hecho de que el silogismo contiene explícitamente como miembro lo que media entre los extremos. Concretamente, el tránsito del juicio al silogismo acontece cuando se hace explícita, en el juicio apodíctico, la unidad determinada del concepto como particularidad ${ }^{27}$ : "ella [la particularidad] es la cópula llena, o plena-de-contenido, del juicio, la unidad del concepto, que ha vuelto a sobresalir a partir del juicio, donde ella estaba perdida dentro de los extremos. - Por medio de este llenado de la cópula, el juicio ha devenido silogismo" (Hegel, 1981: 89).

Para indicar el sentido de esta relación entre el llenado de la cópula del juicio y la estructura general del silogismo conviene acudir a una nota del Differenzsschrift, en la que Hegel cita un pasaje del Timeo de Platón:

27 Los análisis de Düsing y Martin resultan especialmente esclarecedores, especialmente si se atiende a cómo se complementan mutuamente. Düsing (1976: 265) enfatiza el respecto formal de la consumación del juicio como juicio apodíctico: dado que el juicio apodíctico (último juicio del cuarto grupo de juicios, denominado por Hegel como "juicio del concepto") expresa en el sujeto la determinación específica que la hechura o disposición (Bechaffenheit) de la cosa ha de tener para corresponder a su concepto o universalidad concreta —entendida como su naturaleza y fin (Zweck) 一, tanto sujeto como predicado contienen en sí la particularidad; es decir: emerge en ellos expresamente el término medio. Debido a que ellos permanecen todavía dentro de la estructura del juicio, el juicio apodíctico se desdobla en dos juicios: por un lado, se encuentra el sujeto singular y su predicado particular, por otro lado, el sujeto particular y su predicado universal. Debido a que la unidad de ambos juicios está puesta en lo particular, la unidad de ambos juicios constituye la proposición conclusiva de un silogismo. Por su parte, Martin (2012: 296) enfatiza el carácter normativo-evaluativo del juicio apodíctico, subrayando el hecho de que, en términos de contenido, precisamente porque sujeto y predicado contiene, cada uno, la determinación de la particularidad, la cosa debe corresponder a su concepto. Se trata, por tanto, de un componente deontológico que se monta en la concepción ontológica del juicio en Hegel. 
Platón expresa la contraposición real a través de la identidad absoluta del siguiente modo: 'el vínculo [Band] verdaderamente bello es el que se hace a sí mismo uno con lo vinculado. Pues si de tres números, medidas o fuerzas cualesquiera, lo primero es para lo del medio precisamente lo mismo que lo último es para éste, $y$, a la inversa, lo que es lo último para lo del medio es precisamente lo que lo del medio es para lo primero y entonces lo del medio ha devenido primero y último, y a la inversa: lo primero y lo último, ambos, han devenido lo del medio-, entonces serán necesariamente todos lo mismo. (1986: 65)

En cuanto unidad restablecida del concepto, el silogismo no consiste en la restitución de su inmediatez o en la simple borradura de la diferencia puesta en el juicio, sino que la unidad del concepto aparece en él como término medio que pone en relación los extremos. La función vinculante de la cópula se convierte ahora en una determinación del concepto que media las restantes; y sólo a través de esta mediación pone su identidad ${ }^{28}$. En tal sentido, se trata ahora de exponer la unidad del concepto a través de la referencia mutua y explícita de sus tres determinaciones, de modo tal que cada una ocupe tanto la posición de medio entre los extremos como la del resultado de la mediación.

Hegel obtiene el esquema básico del movimiento del silogismo de las tres figuras tradicionales ${ }^{29}$, partiendo por E-B-A, la cual deriva como resultado del juicio apodíctico y considera como la figura fundamental, a la

28 Este es el sentido de que el silogismo conste esquemáticamente de tres juicios, cuestión que para Hegel en todo caso es inesencial o al menos no el aspecto fundamental del silogismo, pues lo que le interesa de aquella forma es subrayar el proceso de mediación contenido en el término medio: "Por eso si el silogismo es considerado meramente como consistiendo en tres juicios, éste es un modo de ver formal, que no menciona la relación de determinaciones, que es lo único que importa en el silogismo" (Hegel, 1981: 94). Más adelante Hegel ironiza: "Todas las cosas son un silogismo, un universal que está concatenado con la singularidad a través de la particularidad; pero naturalmente ellos no son un todo consistente en tres proposiciones" (1981: 95).

29 Sin embargo, no se limita a tomar las figuras de la silogística tradicional, sino también invierte el orden de la segunda y tercera figura, lo cual considera fundado en el desarrollo mismo de las figuras (véase Hegel, 1981: 101). Además, Hegel evita hacer una taxonomía que agote las combinaciones válidas (véase 1981: 108s.) y se concentra en el proceso deductivo que tiene lugar en el desarrollo del silogismo. Por otro lado, Schick (2018: 506507) subraya que no sólo Aristóteles se ofrece como "estofa" de su tratamiento del silogismo, sino que también detecta afinidades con la división tripartita que Kant propone en sus lecciones sobre lógica (Logik-Jäsche): inferencia del entendimiento, de la razón y de la facultad de juzgar (Urteilskraft). Sin embargo, esta "reorganización" de la división kantiana obedece en Hegel a razones relacionadas con la exposición de la propia Lógica: mientras que el silogismo del estar corresponde a la Doctrina del Ser, el silogismo de la reflexión corresponde al curso de la Lógica de la Esencia que avanza hasta la Realidad Efectiva. Finalmente, el silogismo de la necesidad corresponde a la Realidad Efectiva de 
que las restantes pueden ser reconducidas para mantener un rendimiento inferencial. Si se atiende a la relación que Hegel destaca en el "bello vínculo" platónico, entonces resulta claro que el silogismo se completa esquemáticamente si cada determinación de los extremos ocupa la posición del medio, de lo cual resultan las dos figuras restantes: B-E-A y E-AB. Tomando en consideración este hecho, podría sostenerse que la estrategia expositiva del silogismo enfoca el acto de autodeterminación del concepto centrándose cada vez en una de sus determinaciones, de modo que la mediación completa tenga la impronta de la determinación que se ha puesto cada vez como término medio.

Más allá de un asunto meramente combinatorio, esta necesidad se explica porque cada determinación puesta como término medio pone de manifiesto mediaciones implícitas o presupuestas en el proceso general que se lleva cabo; en otras palabras: presenta aspectos diferenciados del movimiento a través del cual el concepto se pone como realidad determinada. De tal suerte, las tres determinaciones puestas como término medio dan lugar a tres silogismos que enfocan cada vez el proceso desde lo particular, lo singular y lo universal; y con ello se ofrece cada vez el contexto en que la determinación llega a ser lo que es en cuanto resultado de un proceso, o sea, como una proposición conclusiva. Esto marca una clara diferencia con el juicio, que se limitaba a aseverar esta última.

De acuerdo con lo anterior, podemos considerar que, en términos generales, la asunción del formalismo del silogismo se relaciona con un proceso en el cual las determinaciones conceptuales de los extremos van poniéndose en el término medio según el esquema ofrecido por sus tres figuras tradicionales, con lo cual el término medio deviene, en cada grupo de silogismos, la unidad de las tres determinaciones del concepto. Cómo esto sucede concretamente, y qué clase de diferenciaciones internas se dan en el proceso es algo que veremos a continuación. Lo importante aquí es indicar que, a través de este proceso, el término medio gana en determinidad conceptual, expandiéndose hasta comprender en sí la totalidad del contenido sustancial en la forma de las tres determinaciones del concepto.

la Doctrina de la Esencia, que conforma el último paso antes del tránsito a la Doctrina del Concepto. Con esto, el tratamiento del silogismo "cubre” la entera Lógica Objetiva. Además, en lo que respecta al uso especulativo (no meramente lógico) de los silogismos (es decir, el núcleo de la concepción formal que Hegel pretende superar en su Lógica), Kant (1998: 428, 437 [KrV A323/B379, A334/B391]) se limita en la Dialéctica Trascendental a los silogismos correspondientes a las categorías de relación: el silogismo categórico (para la idea de alma), el hipotético (para la totalidad de la serie de los fenómenos entendida como fuente de la antinomia) y el disyuntivo (para el ideal de la razón pura en cuanto totalidad de lo pensable en general). 


\subsection{Silogismo cualitativo: el silogismo del entendimiento}

A diferencia del juicio, cuyo tratamiento se organiza en cuatro grupos (juicio del estar, de la reflexión, de la necesidad y del concepto), el silogismo se organiza en tres: silogismo del estar, de la reflexión y de la necesidad. Se trata de tres grupos de tres silogismos en los que puede reconocerse la estructura de mediación ya anunciada. La diferencia entre los tres grupos consiste en el grado de inmanencia y concreción que alcanzan en ellos las determinaciones del concepto, particularmente cuando ocupan la posición de término medio. Pero también difieren porque cada uno expone contenidos y procesos más universales ${ }^{30}$. Lo que esto signifique más precisamente puede inferirse de la reconstrucción de algunos argumentos presentes en el tratamiento de la silogística. Como anunciamos, nos concentraremos en el primer y último grupo ${ }^{31}$ puesto que ellos exhiben el sentido en que el silogismo abarca con su desarrollo la totalidad del contenido sustancial.

El silogismo cualitativo o del estar es el silogismo formal por excelen$\mathrm{cia}^{32}$. Pese a ello, este silogismo es el que presenta los tres esquemas que marcarán el desarrollo del resto de grupos de silogismos y además es su propia carencia de contenido lo que impulsa al silogismo a desarrollarse ulteriormente.

\subsubsection{Las tres figuras del silogismo del estar}

La primera figura del silogismo cualitativo (E-B-A) nos indica que una existencia singular tiene una propiedad entre muchas otras, las cuales, por su lado, son parte de una clase más general. Se trata de una doble relación de subsunción: lo singular (p. ej. una rosa) está subsumido por lo particular (el rojo) que a su vez está subsumido por un concepto más universal (el

30 El tránsito entre los tres grupos se explica porque en cada grupo las determinaciones del concepto se integran en el término medio, con lo cual cada una de ellas adquiere en sí misma también mayor concreción. Valga como ejemplo la diferencia, dentro del esquema E-B-A, entre lo singular del silogismo cualitativo y lo singular del silogismo de reflexión: mientras que, como veremos, lo singular del silogismo cualitativo consiste en el ser de una cosa, lo singular en el silogismo de la suma total (Allheit) es una colección completa de singulares (véase Schick, 2009). Esto es posible sólo porque al final del juicio cualitativo (de modo análogo al paso de la Doctrina del Ser a la de la Esencia, véase Hegel, 1978: 243) se asumió el límite cualitativo, de modo que es posible referir varios individuos bajo un predicado común haciendo abstracción de sus diferencias particulares (por ejemplo en la proposición 'Todos los humanos son mortales' el predicado 'mortal' se aplica a cada humano, sea este Cayo o Alejandro, romano o griego, alto o bajo).

31 Para este punto, además de la bibliografía ya indicada, véase Düsing, 1986.

32 Al respecto, véase Schick, 2003. 
color). De este modo, la premisa menor (Untersaty) enuncia que la singularidad se da una existencia determinada al poseer una propiedad, mientras que la premisa mayor (Obersatz) subsume la particularidad en la universalidad. El silogismo indica entonces que la flor, en su existencia, es de un color, pero no de cualquier color sino de un color determinado. En este esquema, el término medio indica que solamente a través de la determinación lo singular se vincula con la universalidad (es determinación determinada), mientras que la universalidad expresa la posibilidad, en este caso, de que haya flores de otro color o que esa misma flor tenga también otro color.

Se aprecia que la determinación cualitativa exhibe ya un desarrollo, mas tal desarrollo es aún incompleto. Si nos preguntamos por qué la flor es roja y no amarilla, entonces salta a la vista que es la propia singularidad de su existencia la que sostiene la unidad de lo universal y lo particular, de modo que esta vez es la singularidad el término medio (B-E-A) lo que pone la identidad de lo universal y lo particular. Y con esto se revela algo que solamente estaba implícito en el primer silogismo, algo que sin embargo es esencial para la determinación cualitativa en general; a saber: que la unidad de lo singular y lo universal puesta por el primer silogismo se basa en una mera contingencia, pues, de hecho, no existe una conexión necesaria entre la rosa, el rojo y el color. O como señala Schick: "el advenir o no advenir conjunto de dos determinaciones en un objeto singular no decide nada acerca de cómo la relación reciproca de éstas se encuentra universalmente determinada" (2018: 523). En tal sentido, lo universal bien podría existir en otra singularidad y determinarse de otro modo, y a la inversa: lo singular bien podría tener otra propiedad particular que a su vez remitiera a otra universalidad. Pues bien, el hecho de que "lo universal no es en y para sí un particular determinado, pues él es más bien la totalidad de sus particulares" y que sólo "es [...] una de sus especies por medio de la singularidad" (Hegel, 1981: 100) se expresa en la segunda figura del silogismo cualitativo, la cual, a través de la singularidad como término medio, introduce la negación en la universalidad.

A diferencia de la primera figura, en la segunda el término medio es dos veces subsumido (no es subsumente una vez y subsumido la otra): lo singular es sujeto de dos predicados de mayor extensión que no exhiben un vínculo entre sí. Por este motivo, la premisa probada por el primer silogismo (su proposición conclusiva), que elevó la singularidad a universalidad, debe relacionarse negativamente con la particularidad para mostrar que la singularidad es más bien exclusión de una determinación dentro de una universalidad de mayor extensión. En los Apuntes de Libelt (de 1828) Hegel (2015a: 509) da el siguiente ejemplo: 'el caballo tiene 4 patas [,] el caballo es blanco'. Naturalmente, de esto no puede concluirse que 'lo que tiene 4 patas sea blanco' y por eso la forma del silogismo tiene una 
primera premisa afirmativa, otra particular y una conclusión particular: 'el caballo tiene 4 patas, algunos caballos son blancos, luego, algunos (seres) blancos tienen 4 patas'.

Ahora bien, es precisamente esta indiferencia de lo universal frente a su determinación cualitativa concreta lo que manifiesta el tercer silogismo: al mostrarse como una existencia a la que pueden o no advenirle ciertas determinaciones particulares, lo singular mismo se ha elevado a universalidad abstracta, que corresponde al término medio del tercer silogismo (E-AB). Esta vez, se trata de un término medio que es dos veces subsumente y constituye la "verdad del silogismo formal" (Hegel, 1981: 103) puesto que si bien "lo que media como unidad de extremos es, esencialmente, universal [...] la universalidad es cualitativa o abstracta, entonces la determinidad de los extremos no está contenida en ella" (Hegel, 1981: 104). Esto se refleja en el hecho que lo universal abstracto puede subsumir toda determinación de menor extensión, de lo cual no resultaría ningún razonamiento necesario. La única necesidad que puede extraerse de este término medio requiere de una premisa negativa que tenga una conclusión negativa. En los Apuntes de Karl Hegel (de 1831) se señala el siguiente ejemplo: "[?el caballo es blanco, la nieve es blanca['], ahí lo blanco es lo universal, en lo blanco se reúnen caballo y nieve. De ahí resultaría la conclusión, [']el caballo es nieve [']" (Hegel, 2015b: 786). Lo absurdo de la conclusión radica en el hecho que ambas premisas son positivas y lo universal abstracto puede predicarse positivamente de cualquier cosa, pero esto no conduce a conexiones necesarias entre los extremos. Por tanto, el silogismo debería ser del siguiente modo: 'El caballo no es blanco, la nieve es blanca, luego, el caballo no es nieve'. Con esto queda puesta la no-identidad entre lo singular y lo particular en el plano de la universalidad cualitativa o abstracta, lo que revela que la universalidad cualitativa, presupuesta en todo el silogismo como el fundamento de la determinación, es indeterminada: cualquier cosa puede tener una cualidad determinada e igualarse o no igualarse a otra por esa cualidad, pero no existe ninguna necesidad en ello, de manera que se trata de una forma insuficiente en que el concepto se determina en la realidad.

\subsubsection{Insuficiencia del silogismo cualitativo}

Pues bien, con este triple movimiento vemos que, por un lado, la exposición del proceso de determinación cualitativa, al poner como término medio cada una de las determinaciones de los extremos, muestra diversos matices y condicionantes del proceso cualitativo. Pero por otro lado también revela la insuficiencia de lo cualitativo en general, a saber, el carácter abstracto de su infinitud y la contingencia de la determinación cualitativa existente en cada cosa. 
Pasaremos por alto la consideración del silogismo matemático (A-AA) como resultado de lo cualitativo y tránsito al silogismo de reflexión. Más bien quisiéramos apuntar aquí que, en lo relativo a sus esquemas, el silogismo se completa positivamente pese al defecto del contenido de sus determinaciones, pues se verifica una presuposición recíproca de cada una de las premisas del silogismo: la primera figura pone (concluye o prueba) que $\mathrm{E}$ es $\mathrm{A}$, pero sus premisas no están probadas. Por eso, el segundo silogismo debe poner como proposición conclusiva una de las premisas del primer silogismo, valiéndose para ello de la que ya fue probada. De este modo, el segundo silogismo concluye que B es A (i.e. sólo algunos B son A) y el tercero que E es B (i.e. E no es B).

El silogismo cualitativo presenta ya la forma racional del silogismo como un círculo de mediación entre las determinaciones del concepto: cada determinación ha pasado al término medio, con lo cual éste se ha mostrado como totalidad. Pero como toda determinación del inicio, el silogismo cualitativo se encuentra afectado por la inmediatez, lo cual quiere decir concretamente que sus determinaciones conceptuales son todavía "determinaciones abstractas" (Hegel, 1981: 91): están separadas unas de otras y sólo consiguen ser exteriormente enlazadas a través del término medio. Lo propio del silogismo, en cambio, es que cada determinación "está en referencia a la otra, y que el término medio no solamente contiene la particularidad frente a las determinaciones de los extremos, sino que las contiene puestas en él" (Hegel, 1981: 91), vale decir, el término medio debe contener como puestas las tres de terminaciones del concepto, sólo entonces puede hablarse con propiedad de un desarrollo inmanente.

Esta insuficiencia tiene la siguiente consecuencia: porque el término medio contiene las tres determinaciones de un modo abstracto o formal, el silogismo es subjetivo en el sentido anteriormente señalado de 'todavía o meramente formal'. Por eso el fundamento de su referencia recíproca no radica en las determinaciones mismas (i.e. en el término medio, que es lo que posibilita al 'ergo' del silogismo), sino que requiere de una opinión subjetiva exterior que opere como conexión de las determinaciones de la forma. Esto lleva a Hegel a considerar este silogismo como un silogismo del entendimiento, del cual pueden extraerse conclusiones no sólo diversas sino también contrapuestas, pues ellas se basan en la posición exterior que el entendimiento tiene con respecto al contenido ${ }^{33}$. En el mismo sentido,

33 Hegel ilustra el defecto del silogismo del entendimiento con los ejemplos siguientes: "Si se concluye del terminus medius de la sensibilidad, que el ser humano no es ni bueno ni malo, porque de lo sensible no puede predicarse ni lo uno ni lo otro, entonces es el silogismo verdadero, pero la proposición conclusiva es falsa, porque acerca del ser humano, como algo concreto, vale también en igual medida el término medio de la espiritualidad. [...] Igualmente, del terminus medius de la sociabilidad puede seguirse la comunidad de 
puede decirse que el silogismo cualitativo no da con 'definiciones' esenciales de las cosas, pues las cosas tienen, en efecto, muchas propiedades destacables, y es arbitrario cuál se destaque y cuál no. Una definición esencial, en cambio, expone la naturaleza objetiva de lo que se quiere conocer: "la naturaleza de la Cosa está en que las diferentes determinaciones conceptuales de la Cosa están unificadas en la unidad esencial" (Hegel, 1981: 95). Esta insuficiencia no es del silogismo en cuanto tal, sino de la forma inmediata en que las determinaciones del concepto hacen en él su entrada.

Lo anterior nos ofrece una clave para interpretar el sentido del avance del silogismo: El contenido singular que se presenta cualitativamente determinado recién comienza un proceso de mediación a través del cual adquirirá mayor determinación y universalidad. Por este motivo, el desarrollo o expansión de la forma del silogismo, no sólo a través de sus figuras sino principalmente a través de sus grupos (estar, reflexión, necesidad), constituye al mismo tiempo una ganancia de un contenido, el cual no sólo debe ser abarcado en su totalidad por el silogismo, sino también expuesto según sus conexiones necesarias, considerándolas como actividad del concepto, no como predicados de la sustancia.

Con esto queda delineado el sentido del desarrollo del silogismo como forma de autodeterminación del concepto en la sección Subjetividad: el contenido del silogismo cualitativo debe ganar extensión, mientras que la forma del mismo debe realizarse en la Cosa, como su necesidad puesta.

\subsection{Silogismo de la necesidad: la asunción del "formalismo del silogizar"}

El silogismo de la necesidad consuma la exposición del silogismo al re-construir la necesidad de la sustancia a través de las determinaciones

bienes; pero del terminus medius de la individualidad, si es proseguido de un modo igualmente abstracto, se sigue la disolución del estado, en lo que resultó en el Imperio Germánico al haberse atenido a ese último terminus medius" (Hegel, 1981: 96s.). La pregnancia de los ejemplos subraya también algo relacionado directamente con nuestro asunto: ambos casos indican que el contenido puede determinarse de un u otro modo según el término medio que se escoja. Esto indica cierta arbitrariedad en el modo en que el contenido es determinado, pero también indica que no ha sido suficientemente determinado: la reflexión política debe, ciertamente, considerar la individualidad como algo central para la esfera del derecho, pero no tomar en cuenta la centralidad que la sociabilidad tiene para el orden sociopolítico conduce a su desintegración en el atomismo de los muchos unos indiferentes. La idea de Hegel consistiría entonces en que la cosa en sí misma (en este caso: el Estado) consiste en el vínculo de tales dimensiones necesarias, cuestión que puede ser expuesta a través de un sistema de silogismos. Pero la esfera cualitativa no logra superar esta dificultad. 
libres de la subjetividad ${ }^{34}$. Se trata, por tanto, del final del desarrollo del silogismo como forma pura de la subjetividad, lo que no implica que el silogismo deje de jugar un papel en momentos ulteriores de la exposición lógica; más bien sólo indica que como forma pura se ha desarrollado hasta asumirse.

Pues bien, si el juicio fue considerado por Hegel como la "realización más próxima del concepto", el desarrollo del silogismo de la necesidad presenta un nuevo nivel de esta realización. Con este nivel "el concepto en general ha sido realizado", por cuanto "ha ganado una realidad que es objetividad" (1981: 125). Naturalmente, Hegel se refiere con esto al resultado del silogismo, comprendiéndolo esta vez como consumación de la entera sección Subjetividad: cuando el contenido sustancial es determinado por la forma subjetiva pura, entonces este contenido es puesto objetivamente.

Desde el esquema del silogismo, este paso puede entenderse del siguiente modo: la unidad interior del concepto, que ingresó como término medio abstracto en el silogismo cualitativo, va progresivamente exteriorizándose al adquirir forma, forma que ingresó en los extremos abstractos del silogismo cualitativo. Y al revés: la forma, que es lo que en un comienzo se encontraba fuera del término medio entendido como unidad del concepto, ingresa en la interioridad del mismo. En tal sentido puede afirmarse tanto que la realidad ingresa en el concepto, como que el concepto ingresa en la realidad, pues precisamente se ha llegado a la unidad de lo interior (el término medio) y lo exterior (los extremos) del silogismo.

34 Abramovich considera que el silogismo de la necesidad es "el silogismo en la forma del concepto” (2015: 5), lo cual, desde nuestra perspectiva, requiere de una matización. En primer lugar, porque con el silogismo de la necesidad el concepto apenas llega a abarcar la sustancia, cuyo modo de relación (Verbältnisweise) es la necesidad que se manifiesta en la conexión causal. Ciertamente, el sentido de la sección Subjetividad es asumir la sustancialidad a través de la forma del concepto, pero el propio modo de relación del concepto, la libertad, entra como tal en escena desde la asunción de la sustancia en el silogismo de la necesidad y la re-posición del ser de ésta a partir del concepto, como objetividad. Por tanto, reconstruir conceptualmente la necesidad no equivale a exponer la forma del concepto, sino sólo su presuposición: sólo a partir de ahí el concepto puede actuar libremente, ir más allá de la necesidad. En segundo lugar, porque es claro que, a diferencia del juicio, que contiene un cuarto grupo denominado expresamente "juicio del concepto" (sobre cuyo carácter normativo, i.e. práctico, ya hemos llamado la atención), el silogismo se limita a tres grupos. La forma del concepto correspondería a un cuarto grupo de silogismos, lo que - si se examina el surgimiento de la Doctrina del Concepto a partir de las lógicas propedéuticas de Nuremberg- se relaciona con cierta función teleológica del concepto (Düsing, 1976: 289), que Hegel expondrá posteriormente dentro de la sección Objetividad, como tránsito a la idea. 


\subsubsection{Del silogismo de la reflexión a la universalidad concreta}

Para ingresar en la dialéctica del silogismo de la necesidad conviene destacar un aspecto del silogismo de la reflexión. Como acertadamente señala Martin $^{35}$, en el silogismo del estar se intenta mediar la existencia inmediata de un singular con una disposición cualitativa aislada y un universal abstracto, mientras que el silogismo de la reflexión, por haber asumido la diversidad cualitativa, conecta conjuntos de individuos a través de un elemento que los agrupa (el cual a su vez pertenece a una clase específica), de manera que se trata de un silogismo que contiene una reflexión entre la clase que reúne a los individuos a través de un elemento y la suma total (Allheit) de los mismos. En el silogismo de la analogía, correspondiente al tercer esquema (E-A-B) del silogismo de la reflexión, el término medio es "una universalidad que es la reflexión-dentro-de-si de un concreto, siendo por tanto la naturaleza del mismo" (Hegel, 1981: 115). De este modo, se trata de un concepto que se enuncia como singular pero expresa la naturaleza universal de la suma total de individuos pertenecientes a esa esfera, esfera que, a su vez, se encuentra dividida en sub-conjuntos. ${ }^{36}$ Con ello, Hegel considera que se ha llegado al universal concreto, correspondiente a la relación de sustancialidad. Este universal concreto exhibe su desarrollo en el silogismo de la necesidad, donde las determinaciones del concepto son consideradas como género, especie y la instancia de singularización del género.

\subsubsection{Realización del silogismo de la necesidad}

Con el silogismo de la necesidad se abre el espacio para una mediación inmanente: ya no se trata de cualidades, ni de grupos de individuos que se reúnen en virtud de un mero elemento, se trata de exponer la conexión entre el ser de las cosas y su esencia. En tal sentido, Hegel prepara la exposición del silogismo categórico, la primera figura del silogismo de necesidad (E-B-A), sosteniendo que el medio es la identidad interna de los extremos, su naturaleza esencial, mientras que la exterioridad de éstos con respecto a aquél constituye el lado de la aparición inesencial, una forma que todavía no corresponde al contenido de la esencia. De tal suerte, Hegel determina

\footnotetext{
35 Véase, Martin, 2012: 317-138. Para un análisis de los tres silogismos de la reflexión (suma total, inducción, analogía), véase Schick, 2018: 530-542.

36 Para las limitaciones del silogismo de la analogía, véase Iber, 2009: 132-134.
} 
la realización de este silogismo [...] de tal modo que los extremos vengan puestos igualmente como esta totalidad que por lo pronto es el término medio, y que la necesidad de la referencia, que por lo pronto es sólo el contenido sustancial, sea una referencia de la forma puesta. (Hegel, 1981: 119)

El silogismo categórico sólo cumple esta exigencia de realización de un modo inmediato: el término medio indica el género de la existencia singular, que en cuanto particular se encuentra determinado, mientras que la universalidad abstracta indica la determinación del género. A diferencia del silogismo cualitativo, aquí no se trata de un término medio indiferente, por lo que "así se elimina la contingencia de que el sujeto estuviera concatenado silogísticamente con una cualidad cualquiera sólo por un terminus medius cualquiera" (Hegel, 1981: 120). Antes bien, lo mediador es acá la conexión necesaria de los extremos y por este motivo, se afirma en el texto que ya no se trata de un "silogismo subjetivo" (Hegel, 1981: 120) por el lado de su contenido.

No obstante lo anterior, el silogismo categórico presenta el siguiente defecto por el lado de su forma: el vínculo esencial es sólo interno: "la universalidad del término medio es identidad maciza, positiva, y precisamente por eso no es la negatividad de sus extremos" (Hegel, 1981: 120). Esto implica, concretamente, que lo inmediato o singular está en identidad con su género, está subsumido por él, pero a su vez se dan otros singulares cuya determinación no obedece a esa necesidad (igualmente se puede decir: el singular tiene además determinaciones inesenciales). Del mismo modo, desde el lado de la universalidad abstracta se muestra que la especificación del género también podría darse de un modo indiferente a la determinación que el género tiene de hecho en el silogismo. La insuficiencia señalada puede sintetizarse diciendo que hay necesidad en sí, pero también hay realidad efectiva que es indiferente a esta necesidad. Esto torna necesario, en primer lugar, que sea la realidad efectiva de la cosa lo que ponga por sí misma la necesidad, tarea encomendada al silogismo hipotético.

Para Hegel, el silogismo hipotético (B-E-A) supera la carencia del categórico en la medida en que "contiene la referencia necesaria, sin la inmediatez de los términos referidos" (1981: 121), es decir, exhibe la mediación como idéntica con los extremos mediados, de modo tal que se asume la exterioridad de los mismos. Tal mediación necesaria adopta el esquema de la condición y lo condicionado pues la primera premisa del silogismo reza:

\section{Si $A$ es, entonces $B$ es}


Esto muestra que la existencia de A es también la existencia de otro, de manera que si se da la condición (que también podría no darse), entonces se da la condicionado. Al respecto, Hegel añade que es indiferente qué comprendamos aquí bajo 'universal' o 'singular': lo universal puede ser la existencia del conjunto de condiciones que permiten el ser de un singular genérico, pero también puede ser la existencia singular genérica de la cosa, que contiene en sí las condiciones. En ambos casos, lo importante es que una determinación opere como la condición y la otra como lo condicionado, es decir, entender la mediación como conexión necesaria entre el ser de A y B.

Pues bien, lo que agrega la menor no es, entonces, ni la determinación de $A$ ni la de $B$, sino la existencia que permite afirmar la relación de necesidad entre $A$ y B, su identidad sustancial como lo real y efectivo: A es. En consecuencia, la segunda premisa afirma el cumplimiento de las condiciones y esto muestra que el término medio no es sino la conexión inmanente de los extremos, pues su existencia permite concluir que $\mathrm{B}$ es: el tránsito de una existencia en otra.

Ahora, si el término medio del silogismo categórico consistía para Hegel en la "identidad maciza" de la sustancia, que permanecía todavía como algo interior frente a la variedad de formas de la existencia efectiva del singular, el término medio del hipotético no es sino la actividad de la forma que aparece como mediación del contenido sustancial. Con esto, el silogismo disyuntivo se revela como el silogismo que une la forma y el contenido del silogismo de la necesidad.

El silogismo disyuntivo corresponde al esquema de la tercera figura del silogismo cualitativo (E-A-B). En él, la singularidad del término medio del silogismo hipotético se ha elevado a universalidad debido a que se ha puesto desde el lado de la existencia la identidad entre el género y su determinación específica. O de otro modo: la singularidad exhibe la forma - la necesidad de la conexión de las determinaciones del género y la especie- como lo mediador, elevándose con ello a universalidad. Entonces, la universalidad se configura como género o universalidad concreta, lo que implica que, en el silogismo disyuntivo, la exterioridad de los extremos ha sido completamente asumida en el término medio, de manera que su tarea consiste en desarrollar inmanentemente la identidad contenida en él. En tal respecto, Hegel sostiene:

El término medio es, empero, la universalidad llenada con la forma; se ha determinado como la totalidad, como universalidad objetiva desarrollada. Por eso, el terminus medius es tanto universalidad como particularidad y singularidad. (1981: 123s.)

Con este silogismo, el contenido sustancial es puesto en identidad con las determinaciones del concepto. Aquí, la universalidad corresponde a la 
"identidad sustancial del género", mientras que la particularidad exhibe la totalidad de las especies en cuanto "género descompuesto". Por su parte, la singularidad expone el hecho de que el concepto, en cuanto diferenciación, es unidad negativa, por lo que cada momento particular se determina como asunción del resto, siendo con ello único (individualidad reflexionada en sî), de lo cual resulta una "exclusión recíproca de las determinaciones".

Específicamente, el silogismo expone en la primera premisa la identificación entre el género y sus especies, por cuanto se afirma:

\section{$A$ eso $B \circ C \circ D$}

A diferencia de la conexión presente en la tercera figura del silogismo cualitativo, no se trata aquí de una conexión exterior entre lo universal y la particularidad. Pero tampoco de una universalidad que contenga inmediatamente en sí su instancia singular, lo que tiene como consecuencia —en el silogismo de la analogía— que su "predicado [...] no es además predicado de otros singulares" (Hegel, 1981: 117) que están fuera del elemento vinculante (i.e. que pertenecen a otra clase), al menos no necesariamente. La universalidad del género consiste, antes bien, en la diferenciación necesaria de sus especies, de manera que ellas ofrecen la determinación esencial de su contenido, su reflexión inmanente.

Por otra parte, la segunda premisa ${ }^{37}$, la identidad de lo universal y lo singular, expone el momento de la singularización del particular, dado que se afirma:

\section{Pero $A$ es $B$}

La afirmación de la identidad de lo universal con un particular, i.e. singular, implica al menos dos cosas: en primer lugar, que esa identidad no sólo es la asunción del resto de los particulares, sino que también ella solo se da en el contexto ofrecido por ese desarrollo. De esto resulta que la conexión entre los particulares queda contenida en la singularidad como el contexto de su emergencia, aquello que ofrece el sentido de su carácter único. Por otro lado, los particulares son excluidos por el singular, ya que este contiene en sí la universalidad, siendo con ello la negación del resto

\footnotetext{
37 Según Hegel (1981: 124), la segunda premisa del silogismo disyuntivo puede ser tanto la afirmación de la identidad entre lo universal y un particular (o sea, singular), de lo cual resulta la exclusión del resto de los particulares, como la exclusión del resto de los particulares, de lo cual resulta la identidad de lo universal y lo singular.
} 
de las particularidades. Esto último se hace explícito en la proposición conclusiva:

$$
\text { Luego, } A \text { no es } C \text {, ni D }
$$

Ahora bien, debe destacarse, finalmente, que en este silogismo tanto las premisas como la conclusión tienen como sujeto al término medio, lo que indica el nivel de inmanencia alcanzado por este, la concreción del universal. Hacia el final del silogismo de la necesidad, la subjetividad formal alcanza la estructura conceptual correspondiente a la sustancia y las conexiones necesarias puestas por ella y en ella: su necesidad es enteramente puesta por la determinidad del concepto. Con esto, el exceso del contenido de la sustancia con respecto a la forma del concepto puro ha sido asumido en el término medio del silogismo, que contiene en sí los momentos de la universalidad, la particularidad y la singularidad. Del mismo modo, podría decirse que el entero movimiento de la silogística se comprime en un solo silogismo, cuyo término medio expone "el lazo interior de la necesidad" (Hegel, 1981: 124) como actividad conceptual y automovimiento.

\section{CONSIDERACIÓN FINAL}

En el Planteamiento nos propusimos mostrar cómo, en la Ciencia de la Lógica, Hegel restablece el carácter objetivo de la razón a través de la forma del silogismo. Con ello, Hegel se confronta directamente con la operación "des-sustancializadora" de la crítica kantiana, pero también con el pensamiento de Jacobi, quien igualmente considera al silogismo como parte de una razón limitada, contraponiendo a esta otra razón que sería la causa absoluta del mundo, sólo accesible a la creencia en cuanto saber inmediato $^{38}$. La reconstrucción del argumento hegeliano nos ha permitido verificar que Hegel llega a establecer un significado especulativo del silogismo tras el desarrollo de un proceso mediante el cual el silogismo abandona su propio formalismo al construir en sí, a través de las determinaciones puras del concepto, la totalidad del contenido sustancial que antes, en la Lógica

38 En este sentido, Jacobi sostiene en el Beilage VII de la segunda edición de sus Cartas que "si se entiende bajo razón el alma del ser humano, sólo en la medida en que ella tiene conceptos claros, con los cuales enjuicia y silogiza, formando con ello nuevamente otros conceptos o ideas, entonces la razón es una disposición del ser humano que el poco a poco va alcanzando, una herramienta de la que él se sirve, ella le pertenece. Pero si se entiende bajo razón el principio del conocimiento en general, entonces ella es espíritu, de lo cual está hecho la entera naturaleza viviente del ser humano: por ella el ser humano existe; él es una forma que ella ha tomado" (Jacobi, 2000: 286s.). 
Objetiva, había llegado a ser puesto según la determinación de la necesidad. Con ello, el contenido absoluto de la sustancia se transparenta para el concepto, quien reconoce en ella la identidad de su propio hacer.

Para finalizar quisiéramos referirnos concretamente a los interrogantes planteados al inicio, lo que constituye el resultado del presente estudio.

1. Se impone, en primer lugar, la pregunta acerca de qué clase de objeto corresponde al sentido especulativo del silogismo, lo cual se conecta con el resultado del silogismo disyuntivo. En efecto, por un lado, Hegel sostiene que con el silogismo disyuntivo "se ha asumido [...] el formalismo del silogizar y, por ende, la subjetividad del concepto" (1981: 125), frase que puede interpretarse en el sentido correcto, aunque trivial, de que ya no queda nada más por mediar, de modo que no existe la diferencia entre premisas y conclusiones. Pero, por otro lado (y en un sentido más profundo), esta idea expresa que el silogismo disyuntivo "no es ya [...] silogismo ninguno" (Hegel, 1981: 124), pues, al tomarse el medio todo el lugar, se ha conformado una "unidad tan precisamente desarrollada y total como simple" (Hegel, 1981: 125), unidad en la que lo interior puede reconocerse como realidad. De ahí que Hegel sostenga que la entera mediación del silogismo ha puesto al concepto como una nueva inmediatez, siendo el resultado:

Una inmediatez que ha brotado por medio del acto de asumir la mediación: un ser que es precisamente en la misma medida idéntico a la mediación, y que es el concepto, el cual se ha instaurado a sí desde y en su ser otro. Este ser es, por consiguiente, una Cosa que es en y para sí: la objetividad. (1981: 126)

Hegel interpreta la consumación del silogismo disyuntivo como el paso del concepto al ser en el sentido específico de una deducción del carácter objetivo del concepto ${ }^{39}$. A diferencia de Kant, el concepto no es objetivo porque reciba de la sensibilidad la estofa que ha de pensar conforme a reglas, sino porque él mismo ha (tras-)puesto la objetividad a través de su propia

\footnotetext{
39 Por este motivo, lo que en otra esfera se denomina "prueba ontológica de la existencia de Dios", como sabemos, blanco de la crítica kantiana, debe ser remitido en el contexto de la lógica al "entero curso a través del cual el concepto se determina como objetividad". Esto quiere decir que en la objetividad desemboca (no concluye) el proceso que se inicia cuando "él [el concepto] en la singularidad se resuelve [entschließt] como juicio a ponerse como algo real, algo que es; esta realidad todavía abstracta se completa en la objetividad" (Hegel, 1981:127s.). La última frase indica tanto que el curso de la Subjetividad desemboca en la objetividad como que la realización entera del concepto (el paso a la idea) acontece en el interior de una esfera abierta por la objetividad.
} 
forma $^{40}$. El objeto puesto por el silogismo se encuentra, por tanto, esencialmente abierto a su forma, y ello de un modo tal que el concepto pueda reconocerse en él de diversos modos ${ }^{41}$. Con la sección Objetividad se abre una esfera objetiva del concepto ("una Cosa que es en y para sí") que la exposición lógica no abandonará más y en la cual serán tematizados objetos, acciones y estados de cosas (así como transformaciones de dichos estados) entendidos como un contenido conceptual y, en consecuencia, según la forma del silogismo. Esta tematización comienza con el propio contenido sustancial que fue construido según las determinaciones puras del concepto para llegar a ser puesto como objetividad. Prueba de ello es que en los Capítulos Mecanismo y Quimismo Hegel expone las conexiones necesarias (o sea, no libres) entre objetos como un sistema de silogismos.

Basándose en lo anterior, afirmamos que, si el desarrollo del silogismo estuvo marcado por un exceso del contenido sustancial con respecto a la forma subjetiva, el desarrollo a partir de la sección Objetividad está, a la inversa, marcado por un exceso del concepto con respecto al contenido sustancial, de modo que el concepto es libre frente a la necesidad de lo objetivo en general. De acuerdo con esto, el primer modo en que tal libertad se manifiesta consiste en que el concepto pueda exponer la necesidad presente en el mundo objetivo (p.ej. el sistema solar, el Estado) según la forma del silogismo y sus determinaciones puras. No obstante, en un comienzo esta tematización aún no va por sobre la necesidad, sino sólo la expone y reconoce como un desarrollo silogístico objetivo, como un ser-puesto por el concepto.

$40 \mathrm{Al}$ respecto es importante la tesis de Koch que sostiene que la necesidad intra-lógica de la Objetividad radica en mostrar que "el objeto es en él mismo silogismo asumido", vale decir, en probar la objetividad del concepto (el objeto está lleno de, o travesado por, relaciones lógicas que lo constituyen). Esto tiene como consecuencia "que el carácter silogístico del objeto debe manifestarse en el desarrollo lógico" puesto que, en caso contrario, esta prueba de la objetividad del concepto "debe ser de todas formas realizada, pero fuera de la Lógica, presumiblemente al inicio de la filosofía real, recurriendo probablemente a una localización metafísica del tiempo y el espacio al modo kantiano en la Estética Trascendental" (Koch, 2009: 212). Por tanto, para Koch la Objetividad muestra que el concepto puede exhibir una diversidad real sin presuponer por ello una "diversidad espacio-temporal" (2009: 211). Gracias a este paso sería posible una fundación lógico-especulativa de las partes del sistema que ya implican el tiempo y el espacio: la filosofía de la naturaleza y del espíritu.

41 Desde esta idea interpretamos el siguiente pasaje "Dios, como Dios viviente y, aún más, como Espíritu Absoluto sólo es conocido en su hacer [Tun]. Tempranamente le fue indicado al ser humano conocerlo en sus obras; sólo desde ellas pueden brotar las determinaciones que son denominadas como sus propiedades, así como reconocer que también su ser está contenido en ello. Por tanto, el conocer que concibe su obrar [Wirken] i.e. que se concibe a sí mismo, capta el concepto de Dios en su ser y su ser en su concepto" (Hegel, 1981: 128). 
2. Lo anterior nos conduce a la segunda pregunta planteada, a saber: ¿Qué tipo de conocimiento resulta de la correspondencia entre el silogismo y la objetividad? Pues bien, con la integración de las tres determinaciones del concepto en el término medio, Hegel llega a una estructura central para su modelo de exposición especulativa: concebir (Begreifen) significa mostrar desde sí mismo las determinaciones conceptuales que se manifiestan en el (auto)movimiento del 'objeto'; o de otro modo, cómo el concepto se diferencia y especifica en cada determinación. Ya en la Fenomenología, a propósito de la proposición especulativa, Hegel buscó una estructura sistemática como esta por considerarla como la única adecuada para exponer un desarrollo racional, pese a que por entonces aún no la concebía explícitamente como un silogismo (véase Duque, 1990). Con la apertura del contenido absoluto a la forma del silogismo se generan las condiciones para exponer el desarrollo inmanente del 'objeto', considerado como automovimiento del concepto: se trata de un proceso autónomo que contiene en sí mismo el principio de su desarrollo. Por este motivo, su conocimiento no se basa en una reflexión exterior, sino que consiste más bien en la inmersión en la reflexión que el contenido se da a sí mismo. Esto, que operaba implícitamente en la Lógica Objetiva, es explicitado en la Lógica Subjetiva precisamente por medio del concepto de "mostración" introducido a Hegel a propósito de lo singular: la Cosa se muestra a sí misma en el conocer especulativo, el cual, a diferencia del juicio, puede exponer como silogismo procesos objetivos continuos que involucran transformación y permanencia en la transformación. Por esto Hegel reconoce en tales procesos - en diversos modos y grados - un desarrollo conceptual, vale decir, su subjetividad.

3. Como último paso quisiéramos proyectar los resultados obtenidos a los pasos ulteriores de la exposición de la Lógica, lo que se relaciona con los dos puntos recién mencionados.

Señalamos que, con la consumación del silogismo de la necesidad y el surgimiento del Objeto, el exceso de lo sustancial frente a lo subjetivo se invierte en un exceso de lo subjetivo frente a lo objetivo (la subjetividad es ese exceso en la sustancia). Pues bien, aunque la sección Objetividad sólo abre la esfera en la que el concepto ha de desplegar la libertad que ha ganado desde la sustancia, ella también indica que en esta esfera objetiva el concepto debe mostrar su naturaleza libre diferenciándose de la necesidad, para lo cual debe producir libremente la objetividad: transformar el mundo a través de sus propios fines (Zwecke) y herramientas. Por tanto, ya no se trata de tematizar lo necesario como ser-puesto por el concepto, sino además el hacer del concepto mismo como tal, la libre producción de su mundo. En cierto sentido, esto no hace sino corroborar la concepción de lógica subjetiva como una teoría general de la auto-determinación, ahora en un 
contexto en el que el concepto se diferencia de la necesidad dentro de una esfera objetiva.

Desde el capítulo dedicado a la Teleología, la Lógica comienza a exponer silogísticamente una compleja teoría de la acción conceptual, que comienza reconociendo la dimensión instrumental de la racionalidad, para luego integrarla en un concepto universal de vida (entendida como autofin) del cual emerge el conocer humano en su especificidad. Este último paso del proceso de realización del concepto, que abarca la verdad y el bien como sus fines supremos, culmina con el reconocimiento, en la idea absoluta, de la identidad entre el concepto y la realidad que ha sido conocida y transformada por su actividad. Desde la perspectiva de nuestro problema, este último momento -el silogismo de la idea absoluta o método- puede ser considerado como el reconocimiento retrospectivo de la adecuación entre la forma del silogismo y el contenido de la razón (la totalidad de la exposición lógica), anunciada tempranamente en las Tesis de Habilitación. Pero también ofrece la ocasión para interrogarnos críticamente hoy, en la era tecno-lógica, por el tipo de mundo que como especie hemos producido.

\section{REFERENCIAS}

Abramovich, L. (2015). System, Logic, and Metaphysics. A Reading of Hegel's Philosophy from the Point of View of his Theory of the Syllogism. Disponible en: https://www.academia.edu/23667106/System_Logic_and_Me-

taphysics._A_Reading_of_Hegel_s_Philosophy_from_the_Point_of_View_of_his_Theory_of_the_Syllogism .

De la Maza, L. M. (2004). Lógica, Metafísica, Fenomenología. La Fenomenología del Espiritu como introducción a la filosofía especulativa. Santiago de Chile: Ediciones Universidad Católica de Chile.

Duque, F. (1990). Propuesta de lectura de la "proposición especulativa" de Hegel. En F. Duque, Hegel. La especulación de la indigencia (pp. 15-109). Barcelona: Granica.

Düsing, K. (1976). Das Problem der Subjektivität in Hegels Logik. Systematische und entwicklungsgeschichtliche Untersuchungen zum Prinzip des Idealismus und zur Dialektik. Bonn: Bouvier.

Düsing, K. (1986). Syllogistik und Dialektik in Hegels spekulativer Logik. En D. Henrich (Ed.), Hegels Wissenschaft der Logik (pp. 15-38). Stuttgart: Klett-Cotta.

Giuspoli, P. (2002). Objektive und Subjektive Logik. Über die allgemeine Organisation der Hegelschen Logik in den ersten Nürnberger Jahren. HegelStudien, 35, 77-106.

Goretzki. C. (2011). Die Selbstbewegung des Begriffs. Stufen der Realisierung der spekulativen Metaphysik Hegels in den Jahren 1801-1804/05. Hamburg: Meiner. 
Hegel, G.W.F. (1971). Logik, Metaphysik, Naturphilosophie. En G.W.F. Hegel, Jenaer Systementwürfe II, Gesammelte Werke 7 (R-P. Horstmann y J. H. Trede, Ed.). Hamburg: Meiner.

Hegel, G.W.F. (1978). Wissenschaft der Logik. Erster Band. Die objektive Logik 1812/13, Gesammelte Werke 11 (F. Hogemann y W. Jaeschke, Ed.). Hamburg: Meiner. [Ciencia de la Lógica. La Lógica Objetiva, F. Duque, Trad., Madrid: Abada, 2011].

Hegel, G.W.F. (1980). Phänomenologie des Geistes, Gesammelte Werke 9 (W. Bonsiepen y R. Heede, Ed.). Hamburg: Meiner.

Hegel, G.W.F. (1981). Wissenschaft der Logik. Zweiter Band. Die subjektive Logik 1816, Gesammelte Werke 12 (F. Hogemann y W. Jaeschke, Ed.). Hamburg: Meiner. [Ciencia de la Lógica. La Lógica Subjetiva, F. Duque, Trad., Madrid: Abada, 2015].

Hegel, G.W.F. (1984). Wissenschaft der Logik. Erster Band. Die Lehre vom Sein (1832), Gesammelte Werke 21 (F. Hogemann y W. Jaeschke, Ed.). Hamburg: Meiner.

Hegel, G.W.F. (1986). Differenz des Fichte'schen und Schelling'schen Systems der Philosophie. En G.W.F. Hegel, Jenaer Kritische Schriften, Gesammelte Werke 4 (pp. 1-92; H. Buchner y O. Pöggeler, Ed.). Hamburg: Meiner.

Hegel, G.W.F. (1998a). Texte zur Habilitation 1801. En G.W.F. Hegel, Schriften und Entwürfe 1799-1808, Gesammelte Werke 5 (pp. 221-253; M. Baum y K.R. Meist Ed.). Hamburg: Meiner.

Hegel, G.W.F. (1998b). Fragmente aus Vorlesungsmanuskripten 1801/02. En G.W.F. Hegel, Schriften und Entwürfe 1799-1808, Gesammelte Werke 5 (pp. 255-275; M. Baum y K.R. Meist, Ed.). Hamburg: Meiner.

Hegel, G.W.F. (2006). Kurse, Manuskripte und Diktate. En G.W.F. Hegel, Gymnasialkurse und Gymnasialreden 1808-1816, Gesammelte Werke 10/1 (pp. 3265; K. Grotsch, Ed.). Hamburg: Meiner.

Hegel, G.W.F. (2014). Man kan den Zustand. En G.W.F. Hegel, Frühe Schriften II, Gesammelte Werke 2 (pp. 254-259; W. Jaeschke, Ed.). Hamburg: Meiner.

Hegel, G.W.F. (2015a). Sommersemester 1828. Nachschrift Karol Libelt. En G.W.F. Hegel, Vorlesungen über die Wissenschaft der Logik, Gesammelte Werke 23/2 (pp.437-509; A. Sell, Ed.). Hamburg: Meiner.

Hegel, G.W.F. (2015b). Sommersemester 1831. Nachschrift Karl Hegel. En G.W.F. Hegel, Vorlesungen über die Wissenschaft der Logik, Gesammelte Werke 23/2 (pp. 649-808; A. Sell, Ed.). Hamburg: Meiner.

Iber, Ch. (2009). Zum erkenntnistheoretischen Programm der Schlusslehre Hegels mit Blick auf seine Kritik am Verstandesschluss. En A. Arndt, Ch. Iber, G. Kruck (Ed.), Hegels Lehre vom Begriff, Urteil und Schluss (pp. 119-136). Berlin: Akademie Verlag.

Jacobi, F.H. (2000). Über die Lehre des Spinoza. Hamburg: Meiner.

Kant, I. (1998). Kritik der reinen Vernunft, Hamburg: Meiner. [Crítica de la razón pura, P. Ribas, Trad., México D.F.: Taurus, 2006].

Kant, I. (2009). Kritik der Urteilskraft. Hamburg: Meiner. 
Koch, A. F. (2009). Die Problematik des Übergangs von der Schlusslehre zur Objektivität. En A. Arndt, Ch. Iber, G. Kruck (Ed.), Hegels Lehre vom Begriff, Urteil und Schluss (pp. 205-215). Berlin: Akademie Verlag.

Martin, Ch. (2012). Ontologie der Selbstbestimmung. Eine operationale Rekonstruktion von Hegels ,Wissenschaft der Logik." Tübingen: Mohr Siebeck.

Nuzzo, A. (1995). Zur logischen Bestimmung des Ontologischen Gottesbeweis. Bemerkungen zum Begriff der Existenz im Anschluß an Hegel. Hegel-Studien, 30, 105-120.

Nuzzo, A. (2003). Existenz «im Begriff» und Existenz «ausser dem Begriff». Die Objektivität von Hegels «subjektiver Logik». En A. F. Koch, A. Oberauer, K. Utz (Ed.), Der Begriff als die Wabrheit. Zum Anspruch der Hegelschen «Subjektiven Logik» (pp. 171-187). Paderborn: Ferdinand Schöningh.

Okochi. T. (2019). Wissen und Handlung. Zwei Formen der Subjektivität in Hegels Ideenlehre. Presentado en Logik der Moderne. Wissenschaft der Logik als Paradigma moderner Subjektivität, Friedrich-Schiller-Universität Jena.

Rameil, R. (1993). Der teleologische Übergang zur Ideenlehre und die Entstehung des Kapitels «Objektivität» in Hegels propädeutischer Logik. Hegel-Studien, 28, 165-191.

Schäfer, R. (2001). Die Dialektik und ibre besonderen Formen in Hegels Logik. Entwicklungsgeschichtliche und systematische Untersuchungen. Hamburg: Meiner.

Schäfer, R. (2006). Hegels identitätstheoretische Deutung des Urteils. En A. Arndt, Ch. Iber \& G. Kruck (Ed.), Hegels Lehre vom Begriff, Urteil und Schluss (pp. 48-68). Berlin: Akademie Verlag.

Schick, F. (1994). Hegels Wissenschaft der Logik-Metaphysische Letztbegründung oder Theorie logischer Formen? Freiburg / München: Karl Alber.

Schick, F. (2002). Die Urteilslehre. En A. F. Koch \& F. Schick (Ed.), G.W.F. Hegel. Wissenschaft der Logik (págs. 203-224). Berlin: Akademie Verlag.

Schick, F. (2003). Begriff und Mangel des formellen Schliessens. Hegels Kritik des Verstandesschlusses. En A. F. Koch, A. Oberauer \& K. Utz (Ed.), Der Begriff als die Wabrheit. Zum Anspruch der Hegelschen «Subjektiven Logik» (pp. 85100). Paderborn: Ferdinand Schöningh.

Schick, F. (2009). Der Schluss der Allheit. En A. Arndt, Ch. Iber \& G. Kruck (Ed.), Hegels Lehre vom Begriff, Urteil und Schluss (pp. 137-149). Berlin: Akademie Verlag.

Schick, F. (2018). Die Lehre vom Begriff. Erster Abschnitt. Die Subjektivität. En M. Quante \& N. Mooren (Ed.), Kommentar zu Hegels Wissenschaft der Logik (pp. 457-558). Hamburg: Meiner.

Stekeler-Weithofer, P. (2009). Warum ist der Begriff sowohl Urteil als auch Schluss? En A. Arndt, Ch. Iber \& G. Kruck (Ed.), Hegels Lehre vom Begriff, Urteil und Schluss (pp. 24-47). Berlin: Akademie Verlag.

Wildenauer, M. (2004). Epistemologie freien Denkens. Die logische Idee in Hegels Philosophie des endlichen Geistes. Hamburg: Meiner. 